\title{
Development and Characterization of Photocatalytic GaN Coatings by Cold Spray Process
}

\author{
Shaoyun Zhou ${ }^{1}$, Chrystelle A. Bernard ${ }^{1,2,3 *}$, Kesavan Ravi ${ }^{4}$, Hiroki Saito ${ }^{1}$, \\ Yuji Ichikawa1, Kazuhiro Ogawa ${ }^{1,2}$, Shu Yin ${ }^{5}$ \\ ${ }^{1}$ Fracture and Reliability Research Institute, Tohoku University, Sendai, Japan \\ ${ }^{2}$ ELyTMaX UMI 3757, CNRS - Université de Lyon - Tohoku University, International \\ Joint Unit, Tohoku University, Sendai, Japan
}

${ }^{3}$ Frontier Research Institute for Interdisciplinary Sciences, Tohoku University, Sendai, Japan

${ }^{4}$ Indian Institute of Technology (Indian School of Mines) Dhanbad, Dhanbad, India ${ }^{5}$ Institute of Multidisciplinary Research for Advanced Materials, Tohoku University, Sendai, Japan

*Corresponding author email: chrystelle.bernard@ rift.mech.tohoku.ac.jp

\begin{abstract}
For the first time, the low-pressure cold spray (LPCS) process was used to manufacture Gallium Nitride $(\mathrm{GaN})$ films to enhance its photocatalytic properties and decrease its manufacturing cost. The deposition behavior of the GaN powder on stainless steel substrates was investigated. Several specimens, with sparsely deposited agglomerated GaN particles, were prepared under different spray conditions. Quantitative analysis of the evolution of the coverage area, deposited particle count, and average sectional area shows that, upon impact, agglomerated GaN particles disintegrate, leading to large deposition of small particles. By analyzing the cross-sectional area of the deposited
\end{abstract}


particle, no discernible permanent deformation of the substrate was observed. In addition, X-ray diffraction analysis of the coatings and powder indicated that no phase transformation occurred during the process. Based on Williamson-Hall analysis, the broader peaks of the coatings were mainly attributed to the distortions in the GaN lattice rather than changes in the crystallite size. At $400^{\circ} \mathrm{C}$ and $0.6 \mathrm{MPa}$, the deposition efficiency reached $5.3 \%$, and the photocatalytic activities of the coating were about $33 \%$ ( $+9 \%$ compared to the powder). It is attributed to the higher specific surface area and roughness that the coatings exhibit after the breakage of the particles during the cold spray.

Keywords: Cold spray, Gallium nitride (GaN), Photocatalysis, Agglomerated powder, Splat test, Ceramic powder

\section{Introduction}

The world faces serious environmental problems related to air and water pollution. The NOx gases emitted into the air because of human activities, such as the combustion of fossil fuels in large amounts, contribute to acid rain, global warming, and are hazardous to human health (Ref 1). In recent years, significant research progress has been made to reduce pollution and its effects on the environment. Several techniques are used for the treatment of polluted air and water. Compared to other common methods used for depollution, such as precipitation, adsorption on active carbon, selective catalytic or non-catalytic reactions, photocatalysis has emerged as a green and sustainable technology for solar energy conversion and environmental remediation ( $\operatorname{Ref} 2)$. The 
splitting of water into $\mathrm{H}_{2}$ and $\mathrm{O}_{2}$ over photocatalysts by harvesting solar energy as a source of renewable energy has been attracting significant attention worldwide (Ref 3). In addition, because no oxidizing agents, such as ozone, or heat are necessary, photocatalysis appears to be more economical than other methods (Ref 4).

Among numerous photocatalyst materials, fine oxide powders, such as $\mathrm{TiO}_{2}$ or $\mathrm{ZnO}$, have received tremendous attention for the degradation of several environmental contaminants (Ref 5). These powders can easily be prepared using low-cost methods (Ref 6-9), such as combustion, hydrothermal, precipitation, and sol-gel methods (Ref 5, 10). Another interesting material is Gallium nitride $(\mathrm{GaN})$, a nitride ceramic material, which exhibits high photoactivity and chemical stability against photo-corrosion (Ref 11). Kida et al. (Ref 12) demonstrated the photocatalytic properties of powdered GaN, allowing him to decompose water into oxygen and dihydrogen when $\mathrm{GaN}$ is exposed to light irradiation.

Photocatalysis occurring on the external and internal surfaces of the structures, the high surface-to-volume $(\mathrm{S} / \mathrm{V})$ ratio that powdered or nano-porous materials exhibit is a great advantage for enhancing their photocatalytic properties (Ref 13). However, a major drawback lies in the recuperation and recycling of the fine particles suspended in water after use, mainly because of the formation of aggregates (Ref 14). Therefore, the development of nano-porous photocatalytic films manufactured from the powders is of prime interest (Ref 15, 16).

GaN photocatalyst coatings are conventionally obtained through metal organic chemical vapor deposition (MOCVD) (Ref 17), molecular beam epitaxy (MBE) (Ref 18) or hydride vapor phase epitaxy (HVPE) (Ref 19). However, they still have certain disadvantages that need to be resolved. For example, cracks are frequently observed 
after MOCVD (Ref 20), MBE is time-consuming, and HVPE is an expensive and highskill technique. Besides, these three techniques require high temperature operation $\left(>850{ }^{\circ} \mathrm{C}\right)$ which is known to degradate the material photocatalytic properties due to the changes in the surface microstructure (Ref 21). Therefore, a low temperature operating process seems more suitable for retaining the powder's photocatalytic properties within the films.

Thus, for the fabrication of photocatalytic GaN films, a new manufacturing process combining the advantages of rapidity, cost efficiency, and low temperature is essential. Among the various technologies available, the cold spray (CS) process, also known as cold gas dynamic spray process, appears to be a suitable candidate. The CS process is a solid-state coating technique based on the high-speed impact and consolidation of finely divided powder particles on different substrates (Ref 22). The coating was manufactured at a temperature well below the melting point of the sprayed feedstock. In contrast to other thermal spray techniques, such as thermal spray, sol-gel, and sputtering, the CS process has no risk of oxidation, thermal degradation, grain growth, and low energy consumption. Therefore, the CS technique can be considered to be a safe, green, and economical technology because of the absence of high-temperature explosive gases and radiation (Ref 23). Considering that the bonding process by cold spray predominantly involves the prior particle/substrate interactions and following particle/particle interactions (Ref 24-26), meanwhile, ceramic particles not easy to be plastically deformed and melt (Ref 27), the coating formation would be conceivably elucidated from the first layer and following layers, respectively (Ref 28).

In this study, for the first time, GaN coatings on stainless steel substrates using a coldspray process were manufactured. The bonding mechanisms occurring at the interface 
of particle/substrate and particle/particle were investigated using splat and multi-pass tests, respectively. These two deposition processes were investigated to understand the coating formation and build-up. Later, NOx decomposition tests were conducted to evaluate the photocatalytic properties of the cold-sprayed GaN coatings and compare them with those of the GaN powder.

\section{Materials and Methods}

\section{1 Powders and Substrates}

Commercially available GaN powder (Toshima Manufacturing Co., Ltd., Saitama, Japan) with an average particle diameter of $1.7 \mu \mathrm{m}$, ascertained from the particle size distribution results, was used as feedstock to develop photocatalytic active coatings via the low-pressure cold spray (LPCS) technique. The morphology of the feedstock powder was investigated using a field emission scanning electron microscope (FE-SEM, Hitachi SU-70, Tokyo, Japan) equipped with an energy dispersive X-ray (EDX) system for elemental analysis, which was operated at $10 \mathrm{kV}$. The material properties of the $\mathrm{GaN}$ feedstock are listed in Table 1.

GaN powder was cold-sprayed onto as-received and mirror-polished stainless steel substrates. Prior to the cold spray experiments, the surface roughness of the stainless steel substrates were measured using a surface roughness measuring instrument, that is, a surface profilometer (Surfcorder SE300, Kosaka Laboratory Ltd., Tokyo, Japan) (Ref 26). As illustrated in Table 1 , the mean roughness $(\mathrm{Ra})$ and the maximum height of the profile $(\mathrm{Rz})$ of the as-received stainless steel substrates are $0.10 \pm 0.012 \mu \mathrm{m}$ and $0.83 \pm 0.076 \mu \mathrm{m}$, respectively. After mirror polishing, the values of $\mathrm{Ra}$ and $\mathrm{Rz}$ decreased to $0.06 \pm 0.012 \mu \mathrm{m}$ and $0.39 \pm 0.101 \mu \mathrm{m}$, respectively. Subsequently, the 
Vickers hardness of stainless steel was measured at $216 \mathrm{HV}$ by microhardness testing system (Fischerscope HM2000, Helmut Fischer) (Ref 26).

\section{2 Splat Test and Coating Build-up}

Cold-spraying was performed using the DYMET-423 equipment (Obninsk Center for Powder Spraying, Obninsk, Kaluga, Russia), which comprises an internal gas heater in the spraying gun. Figure 1 reveals a schematic illustration of the downstream injection cold spray apparatus used for the experiment. The spraying gun was attached to a manipulator (BZT Maschinenbau GmbH, Leopoldshöhe, Germany) moving at the same traverse speed. To control the standoff distance between the nozzle and substrate surface, and the traverse parameters, the substrate was mounted on an XYZ stage and manipulated by a personal computer (Ref 30$)$.

Coating formation by cold spray technique can be considered as a two-step process: development of the first layer followed by the coating build-up (Ref 28). In that regards, the splat test appears as an ideal experimental approach for the study of the singleparticle impact and particle/substrate interaction. Splat tests were performed on mirrorpolished stainless steel substrates to remove the effects of the mechanical interlocking (Ref 31).

In total, six spray conditions (three inlet gas temperatures and two inlet gas pressures) were investigated for splat tests to characterize the deposition quality of the $\mathrm{GaN}$ powder on the mirror-polished stainless steel substrate (Table 2). A low feeding rate of $0.019 \mathrm{~g} / \mathrm{s}$ was used to impinge particles sparsely onto the substrate, resulting in no overlapping of the particles. After the test, the particle/substrate interface was investigated, highlighting the deformation and deposition mechanisms of GaN ceramic particle on a metallic substrate. 
After understanding the development of the first layer and the deposition mechanisms between $\mathrm{GaN}$ particle and stainless steel substrate, coating build-up was performed. The same spray conditions as for splat tests were used (see Table 2). As it was proven than an initial substrate roughness promotes the mechanical interlocking and coating buildup (Ref 32), coating build-up experiments were performed on as-received substrates.

\section{3 Characterization of the First Layer Deposition Behavior}

Back-scattered electron (BSE) micrography (FE-SEM, Hitachi SU-70, Tokyo, Japan) was used to study the deposition behavior of the GaN particle after the splat tests. Sixteen BSE images were taken from the center to the edge of the spray position, perpendicular to the spray direction, at a magnification of $\times 500$ (Fig. 2), covering a surface of $3 \mathrm{~mm} \times 254 \mu \mathrm{m}$. Meanwhile, to investigate the deposition behavior of the deposited particles, higher magnification images $(\times 2500)$ were also taken at the center of each BSE image (at a magnification of $\times 500$ ) (Fig. 2). Each BSE image was processed using the open-source software ImageJ. The study mainly focused on the identification of the number of particles being deposited, their location of deposition, and the coverage area on the substrate for each spray condition. Therefore, the deposition behavior of the GaN particles onto a stainless steel substrate was investigated and analyzed quantitatively.

\section{4 Coatings Build-up Characterization}

Sixteen passes of GaN powder were cold-sprayed onto the as-received stainless steel substrates to form thick coatings. The influence of the spray conditions (gas temperature and pressure, see Table 2) on the coating build-up were investigated to understand their effect on the coating characteristics and the particle/particle bonding mechanisms. 
During the spray tests, the deposition efficiency (DE) was concluded according to the ratio of the mass of the deposited powder to the mass of the sprayed powder (Ref 26). Before the SEM characterization, the thick coating specimens were embedded in a water-free epoxy resin, ground with $\mathrm{SiC}$ sandpaper, polished initially with a $3 \mu \mathrm{m}$, and subsequently with a $1 \mu \mathrm{m}$ diamond polishing compound with colloidal silica suspension before immersion in an ultrasonic bath. This procedure helped produce mirror-polished specimens for SEM analysis without any impurities generated from the polishing step. Phase analysis of the GaN powder and coatings samples were carried out using X-ray diffraction (XRD-7000, Shimadzu Scientific Instruments, Tokyo, Japan) with CuKa radiation having a wavelength of $1.5406 \AA$, operated at an acceleration voltage of $40 \mathrm{kV}$ and an emission current of $30 \mathrm{~mA}$, with $2 \theta$ from $10-80^{\circ}$, using a step size of $0.02^{\circ}$ and a scan speed of $2.4 \mathrm{~s} / \mathrm{step}$.

\section{5 Material Coating Characterization for Photocatalytic Properties}

The NOx photocatalytic decomposition process offers an effective way for the abatement of NOx gas, particularly under sufficient visible-light irradiation (Ref 33).

As illustrated in Fig. 3, the photocatalytic properties of the GaN powder and coldsprayed GaN coatings on the stainless steel substrates were evaluated using NOx decomposition tests. Before the test, the NO gas concentration was set at $1 \mathrm{ppm}$, and was prepared by mixing compressed air with $\mathrm{NO} / \mathrm{N}_{2}(2 \mathrm{ppm})$. The mixed gas was continuously introduced into the reactor at a flow rate of $200 \mathrm{~mL} / \mathrm{min}$. Notably, the powder was poured in a $40 \times 40 \mathrm{~mm}^{2}$ glass sample holder to ensure the same surface area of the coated specimen. As for the coated specimen all under a deposition area of $40 \times 40 \mathrm{~mm}^{2}$ in stainless steel substrates, the sample holder was placed on the stage inside the reactor to perform photocatalytic test. Thereafter, the reactor was placed in 
the dark for 30 min under continuous NO gas flow of $1 \mathrm{ppm}$ concentration, to reach a dynamic adsorption-desorption equilibrium of NO gas. After the pretreatment, the tests were carried out at room temperature $\left(25^{\circ} \mathrm{C}\right)$ and a $450 \mathrm{~W}$ high-pressure mercury $(\mathrm{Hg})$ lamp irradiation for $10 \mathrm{~min}$ (Ref 33) in different light wavelengths. During irradiation, filters were selected for controlling the light wavelength $(\lambda)$ in the photocatalytic reaction, that is, Fuji triacetyl cellulose filter for $\lambda>510 \mathrm{~nm}$, Kenko L41 Super Pro (W) filter for $\lambda>400 \mathrm{~nm}$, and Pyrex glass for $\lambda>290 \mathrm{~nm}$ (Ref 34). Besides, the Hg lamp was cooled by a circulating water flow generated using a Pyrex jacket. After each irradiation test under different wavelengths, the sample was placed in the dark for $10 \mathrm{~min}$ by blocking the light, to return to the initial NO concentration.

During the photocatalytic reaction, the gas was directly delivered to a NOx analyzer (Yanaco ECL-88A, Kyoto, Japan) to measure the NO concentration. Thus, the deNOx ratio is defined by:

$$
\text { deNOx ratio }=\frac{C_{0}-C}{C_{0}} \times 100 \% \text {, }
$$

where $C_{0}$ and $C$ are the initial and actual concentrations of NOx gas, respectively, obtained after the photocatalytic reaction.

\section{Results and Discussion}

\section{1 Characterization of the Feedstock Powder}

The SEM images of the feedstock powders are displayed in Fig. 4. Nano-sized particles (Fig. 4 (a)), with an average sectional area of $0.026 \mu \mathrm{m}^{2}$, were naturally agglomerated into micro-sized particles (Fig. 4 (b)). These micro-sized particles possessed an ellipsoidal shape. Based on the results of particle size distribution using the RosinRammler model provided by Nikkiso Co. Ltd., (Tokyo, Japan) (Ref 35), the mean 
particle diameter was estimated to be $1.97 \pm 0.013 \mu \mathrm{m}$, which can be considered as the average length of the agglomerated micro-sized particles. From the SEM images, the average width and sectional area were found to be $0.74 \pm 0.086 \mu \mathrm{m}$ and $1.50 \pm 0.045 \mu \mathrm{m}^{2}$, respectively. Owing to their small sizes and high surface areas, they are also strongly affected by the electrostatic surface charge and van der Waals forces, leading to the formation of super agglomerated particles (Fig. 4 (c)) (Ref 29). In particular, the super agglomerated particles exhibited a porous microstructure.

\section{2 First Layer Formation}

Splat tests were performed on mirror-polished stainless steel substrates to analyze the particle deformation behavior and its bonding mechanisms with the substrate in absence of mechanical interlocking (Ref 36). Like most ceramics, bulk GaN exhibits a brittle behavior (Ref 37-38). However, it was demonstrated that when the material size is reduced to the nanoscale, even diamonds can undergo plastic deformation (Ref 39). Considering the brittle-to-ductile transition occurring at the nanoscale, the yield/fracture strengths show a strong size effect, which increase with the decrease of the material size (Ref 40).

During splat tests, the original super agglomerated GaN particles, composed of microsized particles, would exhibit "pseudo deformation", which attribute to the disintegration of its inherent component micro-sized particles. Therefore, resultant deagglomeration of the micro-sized and super agglomerated particles due to the breakage of van der Waals bonds (Fig. $4(a-b))$. At the same time, higher extent of the breakage of the deposited particles was attributed to the increasing changes of impact energy by gas temperature and pressure. Therefore, the splat formation is mainly 
derived from the rearrangement of the interlinked micro-sized particles within the super-agglomerates.

The strategy to quantify the deposition tendency by counting the deposited particles under each impinging position is demonstrated in Fig. 5 under the spray conditions of $25^{\circ} \mathrm{C}$ and 0.6 MPa. From the BSE images (Figs. 5 (a) and (b)), the number of particles deposited was counted, correlated to their cross-sectional area, and reported in the histogram (Fig. 5 (c)). The histogram displays the results of the deposited micro-sized particles (with an average sectional area greater than $10 \mu \mathrm{m}^{2}$ ) exhibited in Fig. 5 (a) (at a magnification of $\times 500$ ) and the nano-sized particles (with an average sectional area between $0.02-10 \mu \mathrm{m}^{2}$ ) exhibited in Fig. 5 (b) (at a magnification of $\times 2500$ ) as a function of the coverage area. Considering the initial particle size distribution and the ellipsoidal shape of the particles, an average length to width ratio equal to 3 can be assumed. The estimated particle area of the feedstock was compared with the area of the deposited particles (Fig. 5 (c)). As illustrated in the histogram, a large number of nano-sized particles are deposited on the substrate. However, the surface area of these particles do not appear in the feedstock powder. Therefore, to account for the initial particle feedstock, it can be assumed that the van der Waals bonds and electrostatic forces are weakened by the impact of the particles on the substrate, leading to the deagglomeration of the particles. Afterward, an increase revealed in the nano-sized particles being deposited onto the substrate, while the scattered super-agglomerated particles can be deposited. Therefore, the original micro-sized particles (Fig. 4 (b)) disintegrated into nano-sized particles (at an average sectional area between 0.02 and $10 \mu \mathrm{m}^{2}$ ), while the super agglomerated particles (Fig. 4 (c)) exhibited pseudo-deformation (non-plastic deformation but deagglomeration into new shape) to micro-sized particles (at the 
average sectional area greater than $10 \mu \mathrm{m}^{2}$ ), which mainly attribute to the disintegration of its inherent component micro-sized particles

After the splat tests, the evolution of the substrate coverage area along the half-width of the spray area for different spray conditions is reported in Fig. 6. At the same gas pressure, compared to the slope of the substrate coverage area, the slope of the coverage area increased with an increase in the gas temperature. Similarly, at the same gas temperature, a higher coverage area of the substrate was obtained on increasing the gas pressure. At the outskirts of the spray area, the saturation of the coverage area was observed. Therefore, at the center of the spray position, the deposition of a large number of nano and original micro-sized particles (Fig. 5 (c)) resulted in a larger coverage area on the substrate, in contrast to the few super agglomerated particles deposited at the outskirts of the spray area. As discussed earlier, under the same spray parameters of traverse speed and stand-off distance, the conditions of $400{ }^{\circ} \mathrm{C}$ and $0.6 \mathrm{MPa}$ enabled the particles to cover $28 \%$ of the coverage area deposited on the substrate, as compared to nearly $0 \%$ at a temperature of $25{ }^{\circ} \mathrm{C}$. Therefore, a higher gas pressure and temperature of the spray would induce higher efficiency for deposition.

Along the half-width of the spray area from the center to the edge, the evolution of the coverage area and the number of micro or nano-sized particles were evaluated under each spray condition, as illustrated in Fig. 7. Figure 7 (a), (c), and (e) correspond to the results obtained with an initial gas pressure of $0.4 \mathrm{MPa}$, whereas Figure 7 (b), (d), and (f) were obtained by analyzing the specimen cold-sprayed at $0.6 \mathrm{MPa}$. The three investigated gas temperatures are presented.

For each figure, the initial slope at $400{ }^{\circ} \mathrm{C}$ was smaller than that at the other temperatures. Fig. 7 (c) and (d) display the saturation of the curves corresponding to the 
number of micro-sized particles getting deposited at the positions of $1500 \mu \mathrm{m}$ and $2300 \mu \mathrm{m}$, respectively. However, the saturation of the curves in Fig. 7 (e) and (f) is not evident. Therefore, the deposited micro-sized particles are localized close to the center of the spray area, while the distribution of the nano-sized particles was more uniform. At $0.4 \mathrm{MPa}$, no significant difference was observed between the three temperatures in terms of the normalized coverage area and the number of deposited micro- and nanosized particles. Nevertheless, at a pressure of $0.6 \mathrm{MPa}$, close to the center of the spray area for specimens sprayed at $25^{\circ} \mathrm{C}$, a higher normalized coverage area of the substrate and number of deposited nano-/micro-sized particles were observed as compared to those at the two other temperatures.

Considering the Pearson product-moment correlation coefficient $r$ obtained by linear least squares regression analysis, when $\mathrm{r}^{2}$ (coefficient of determination, varies between 0 and 1) is closer to 1 , a more linear relationship is obtained between the investigated parameters and spray position (Ref 41$)$. Therefore, when $r^{2}$ is close to 1 , it represents a more constant deposition of the particles and splat coatings from the center to the edge of the half-width spray area. For the different spray conditions, the coefficient of determination $\mathrm{r}^{2}$ was determined and reported in Table 3 . At $400{ }^{\circ} \mathrm{C}$ and $0.6 \mathrm{MPa}$, the coefficient of determination was found to be relatively higher than that for all the other conditions.

On Fig. 8, for each spray condition, the relationship between the number of deposited particles, their coverage area, and their position along the spray area is plotted. For each condition, the number of deposited nano-sized particles always tends to decrease from the center position to the edge. Meanwhile, under the same spray position, higher 
temperature or pressure conditions always resulted in deposition of a higher number of nano-sized particles.

The average particle size (cross-sectional area) of disintegrated nano-sized particles, sprayed at $400{ }^{\circ} \mathrm{C}$ and $300{ }^{\circ} \mathrm{C}$, decreased distinctly from the center to the edge of the impinging position, meaning that relatively smaller disintegrated nano-sized particles would be preferentially deposited than the bigger particles. Moreover, it is evident that a higher gas pressure and temperature could provide a higher energy for the particles to disintegrate; therefore, the average area size would also be influenced by a smaller size. For the condition of $400{ }^{\circ} \mathrm{C}$ and $0.6 \mathrm{MPa}$, the evolution of the substrate coverage area exhibited a higher efficiency for the formation of the first layer. In addition, the evolution of the coverage area and the number of deposited particles proved a more constant deposition of the particles from the center to the edge of the spray area. Therefore, $400{ }^{\circ} \mathrm{C}$ and $0.6 \mathrm{MPa}$ appears to be the best spray conditions for deposition of GaN powder on stainless steel substrate.

\section{3 Cross-section Observation of Single Deposited Particle Deformation Behavior}

To investigate the microstructure and deformation behavior of the particles and substrate after the splat tests, a single deposited particle (micro-size) at $400{ }^{\circ} \mathrm{C}$ and 0.6 MPa was cut by a (focused ion beam) FIB. The SEM images of the cross-sectional area morphology at a tilt angle of $45^{\circ}$ are displayed in Fig. 9 (a). The deformation of the substrate was not observed after the splat tests. In addition, the interface between the substrate and particle did not exhibit any sign of delamination, cracks, or micro-size porosity (Fig. 9 (b)). 
Based on the topographical morphologies in Fig. 9 (c) of deposited particles derived from Fig. 4 (c) super agglomerated particles, it is notable that the shape of the original super agglomerated particles in the starting feedstock has been transformed from approximate spherical to flat contour, which undergoes non-plastic deformation but deagglomeration into a new shape. It implied that the inherent components, adjacent micro-sized particles disintegrated into nano-sized and then deagglomerated together, result in compressive stress increase, thereby reducing the initial void within the super agglomerated particles. Simultaneously, as shown in Fig. 9 (d) surrounded the super agglomerated deposited particles, the original micro-sized particles in Fig. 4 (b) disintegrated into nano-sized particles and then deposited. Therefore, the deformation is entirely localized within the particle of different extent of disintegrated for micro-sized and super agglomerated particles (Ref 42). Hence, after dissipation, for particle pseudodeformation, breakage, and deposition, the energy remaining was insufficient to lead to substrate deformation.

\section{4 Coating Build-up Characterization}

Considering the above discussions, $400{ }^{\circ} \mathrm{C}$ and $0.6 \mathrm{MPa}$ proved to be the better spray conditions for particle deposition under splat tests. To optimize the properties of the thick coatings (coating build-up), multi-pass tests were carried out for the six spray conditions under 16 passes. The as-received substrates with initial roughness were used to enhance the mechanical interlocking and improve the deposition of the first layer. Theoretically, multiple layer formation slightly influenced by the original substrate roughness which mainly in the first layer formation, at the same time, the deformation extent of the substrate will be improved with the passes number increase which attributes to energy obtained from bombardment particles successive impact. 
SEM images of the coating build-up after 16 passes, for each spray conditions, are presented in Fig. 10. From these images, the thickness was measured using ImageJ software and reported in Fig. 10. At room temperature, no thick coating was obtained independently of the gas pressure used. Thus, the particles could not be completely deposited onto the substrates with low kinetic energy. By increasing the gas temperature and pressure, a thick GaN coating on stainless steel substrate was obtained. In addition, with the increase of the gas temperature or pressure, the average thickness of the coatings also increased. For the obtained coatings, the deposition efficiency was calculated and reported in Fig.11. Even though it remains low, higher deposition efficiency was reported for the spray condition of $400^{\circ} \mathrm{C}$ and $0.6 \mathrm{MPa}$.

Most of the deformed particles seem to be interlocked with their counterparts, creating more stable interfaces. Higher gas temperature or pressure also increases the substrate deformation due to the continuous particles' bombardment on its surface, resulting in an increase of the deposition efficiency. Therefore, upon the impact of the particles, higher substrate roughness is induced, leading to the enhancement of the mechanical interlocking. It also suggests that the compressive stresses induced by the impact help to close the nano-micro pores within the particles resulting in a very dense coating. Therefore, the particles are well packed and interlocked with each other in cold-spray coatings (Ref 42). According to this and the former results, $400{ }^{\circ} \mathrm{C}$ and $0.6 \mathrm{MPa}$ appear to be the better spray conditions to obtain a thick coating on the stainless steel substrate.

\section{5 Evolution of the Coating Crystallite Size}

XRD tests were performed before measuring their photocatalytic properties to verify the crystalline structures of the sprayed GaN coatings and powder. The spray conditions, roughness, and thickness for each specimen are listed in Table 4. The different GaN 
coatings (G1-G4) were cold-sprayed under the same pass number, but different spray conditions (gas temperature and pressure). In addition, it should be noted that G4 corresponds to the specimen sprayed under the best conditions for particle deposition and coating build-up $\left(400{ }^{\circ} \mathrm{C}\right.$ and $\left.0.6 \mathrm{MPa}\right)$.

A comparison of the XRD patterns of the feedstock powders, stainless steel substrate, and cold-sprayed GaN coatings on stainless steel substrates (G1, G2, G3, and G4) is depicted in Fig. 12. The diffraction pattern of the GaN powder exhibited 11 peaks corresponding to the different orientations of the crystalline phase. Using the pdf cards of the hexagonal wurtzite structure GaN (JCPDS, No. 74-0243) (Ref 43), the crystalline orientation related to each peak was identified and presented in Fig. 12.

The XRD diffraction patterns of the GaN coatings on the stainless steel substrates exhibited the same crystalline phase of the hexagonal wurtzite structure of the GaN powder (diffraction peak at the same position). Therefore, the cold-spray process does not lead to anyphase transformation of the GaN powder. The photocatalytic properties of the powder should be retained within the coating.

Compared to the GaN powder, it can be observed from Fig. 12 that the XRD spectra of the coatings fabricated from the LPCS process exhibit broadened peaks. To understand the evolution of the width in the diffraction peak, a simplified integral breadth method, the Williamson-Hall method, is used. This method considers the effect of the straininduced XRD peak broadening and can be used for the calculation of the intrinsic strain along with the particle size (Ref 44$)$.

The physical line broadening of the X-ray diffraction peak occurs because of the size and micro-strain of the nanocrystals, and the total broadening $\beta_{\text {total }}$ can be expressed 
by size-induced peak broadening, $\beta_{\text {size }}$, and strain-induced peak broadening, $\beta_{\text {strain }}$, (Ref 45):

$$
\beta_{\text {total }}=\beta_{\text {size }}+\beta_{\text {strain }}
$$

By considering the strain in all the crystallographic directions to be uniform, the material can be considered as isotropic, i.e., its properties are independent of the direction chosen for the measurement. Therefore, $\beta_{\text {strain }}$ is related to the residual strain $\varepsilon$ by $(\operatorname{Ref} 45)$ :

$$
\beta_{\text {strain }}=4 \varepsilon \tan \theta \text {. }
$$

The origin of Eq 3 may be understood by taking the differential of the Bragg equation with respect to the d-spacing and diffraction angle.

Sample-induced peak broadening is a convolution of the effects due to both the crystallite size and stress. The total sample broadening is usually approximated as the sum of the terms expressed in Eqs 2 and 3:

$$
\beta_{h k l} \cos \theta=\frac{k \lambda}{D}+4 \varepsilon \sin \theta
$$

where $\beta_{h k l}$ is the total broadening due to the strain and size in a particular peak having the value $h k l, D$ is the crystallite size, $k$ is the shape factor constant equal to 0.94 , and $\lambda$ is the wavelength of the X-ray $(0.1542 \mathrm{~nm})(\operatorname{Ref} 46)$.

Fig. 13 presents the plot of Eq 4 for the GaN coatings and powder, with $4 \varepsilon \sin \theta$ along the $\mathrm{X}$-axis and $\beta_{h k l} \cos \theta$ along the $\mathrm{Y}$-axis. Only the four main diffraction peaks were represented, (100), (002), (101), and (110). In this case, the other peaks were not included in the analysis because their intensities were not sufficiently strong to allow the meaningful fitting of their peak shapes. 
Based on the least-squares linear approximation of these four peaks, the crystallite size and strain were approximated (Ref 47). According to Eq 4, the slope of the linear approximation corresponds to the intrinsic strain $\varepsilon$, whereas the intercept allows the calculation of the crystallite size D. For each specimen, based on the values for the strain and crystallite size that reported in Table 5, tensile strains were generated under the GaN coatings after cold spray process (Ref 48 ). As the average crystallite size for the GaN powder and each coating is almost the same, the magnitude of the strain broadening greatly exceeded the broadening due to crystal size. Therefore, the distortions in the lattice of $\mathrm{GaN}$ are the main source of the broadening of the diffraction peaks, which arise from the gradients in the micro strains induced by tensile forces. Because the broadening of the diffraction peaks due to the changes in the crystallite size is relatively low (Ref 45), the CS process does not involve any microstructural change to the particle when coated.

\section{6 Photocatalytic Properties of Cold-sprayed GaN Coatings}

After the identification of the crystalline structures of the prepared samples (as-sprayed GaN coatings and powder), the photocatalytic activity was evaluated by the decomposition of $\mathrm{NO}_{\mathrm{x}}$ gas under visible light irradiation in a continuous gas-flow reactor. As listed in Table 4, the roughness and thickness values for each specimen were also measured.

$\mathrm{NO}_{\mathrm{x}}$ decomposition tests were performed to evaluate the photocatalytic properties of our specimens. As illustrated in Fig. 14, under UV light (10-400 nm), GaN proved to be effective for the photocatalytic degradation of dyes. Among them, the photocatalytic properties of the cold-sprayed GaN coatings were approximately $33 \%$, which was $9 \%$ higher than the $\mathrm{DeNO}_{\mathrm{x}}$ ratio of the GaN powder (approximately $24 \%$ ). 
As discussed earlier, the cold-sprayed GaN coatings exhibited higher photocatalytic properties than the GaN powder. Because the coatings and powder exhibit the same phase (Fig. 11) and crystallite size (see Table 5), it can be assumed that the enhancement of the photocatalytic properties is related to the evolution of the coating surface morphology.

After the LPCS process, no significant change was observed in the crystallite size, and the coatings did not include any impurities. Only a large difference in the strain between the powder and coatings is observed, which is induced by the tensile forces. It has been reported that photocatalysis is a surface reaction; hence, the photocatalytic properties are affected by the surface morphology (Ref 15). Considering the deformation or breakdown of the feedstock powder and the average sectional area of the disintegrated nano-sized particles (Fig. 8), the agglomerated particles tend to break into smaller parts. The same tendency is observed for multi-pass tests. Because of the severe breakage of the deposited particles, a decrease in the particle size and an increase in the surface area of the deposited particles were observed in accordance with the evolution of the gas temperature and pressure. Therefore, increasing the gas temperature and pressure led to better photocatalytic properties of the GaN coatings compared to those of the $\mathrm{GaN}$ powder.

As mentioned, photocatalysis is a surface reaction. Therefore, the DeNOx ratio is also evaluated as a function of coating thickness and roughness (see Fig. 15) (Ref 49). The decomposition NO conversion ratio increases with increasing thickness and roughness of the different samples. In particular, considering that G2 shown a relatively higher decomposition NO conversion ratio with higher roughness but lower thickness than G3. Thus, a higher roughness of the coatings will be more helpful to increase the 
photocatalytic activity of the GaN films manufactured by the CS process. The enhancement of the $\mathrm{S} / \mathrm{V}$ ratio of the coatings will be necessary to improve their photocatalytic properties.

\section{Conclusion}

In this study, for the first time, nano-porous and photocatalytic active GaN coatings were fabricated with GaN agglomerated powder using the LPCS system. Based on the splat test results and quantitative analyses under different spray temperatures and pressures, the best spray conditions were determined to be $400{ }^{\circ} \mathrm{C}$ and $0.6 \mathrm{MPa}$. Upon the impact on the substrate, the agglomerated micrometer-sized GaN particles disintegrated, with a large number of the deposited disintegrated particles observed at the nozzle axis of the traversed area. Furthermore, the critical impact energy was measured for particles subjected to the highest gas pressures and temperatures, thereby improving the fragmentation of the agglomerated particles and the deposition efficiency during the process. Meanwhile, no discernible permanent deformation of the substrate was observed according to the cross-sectional observation by FIB.

Multi-pass tests were performed in a stainless steel substrate, and changes in the average thickness were evaluated for different gas temperatures and pressures. From the XRD patterns of the coating, powder, and substrate, no phase transformation of the material was observed before and after spraying. In addition, the Williamson-Hall analysis exhibited no significant changes in the crystallite size after spraying. However, a large increase in the intrinsic strain after cold spray induced a broadening of the XRD peaks. Finally, the NOx decomposition test was conducted to evaluate the photocatalytic properties of the cold-sprayed GaN coatings. Higher decomposition of NO gas was 
reported for the cold-sprayed specimen under UV light (approximately 33\%) than for the GaN powder, mainly because of the surface area enhancement after cold spraying without any photocatalytic property degradation. Therefore, a higher thickness and roughness would be beneficial for improving the photocatalytic properties of the $\mathrm{GaN}$ coatings.

\section{Acknowledgements}

This study was partly supported by the JSPS KAKENHI Grant-in-Aid for Scientific Research (A) 17H01235. 


\section{References}

1. J. Ângelo, L. Andrade, L.M. Madeira, and A. Mendes, An Overview of Photocatalysis Phenomena Applied to NOx Abatement, J. Environ. Manage., 2013, 129, p 522-539, doi:10.1016/j.jenvman.2013.08.006.

2. F.L. Toma, G. Bertrand, S. Begin, C. Meunier, O. Barres, D. Klein, and C. Coddet, Microstructure and Environmental Functionalities of $\mathrm{TiO}_{2}-$ Supported Photocatalysts Obtained by Suspension Plasma Spraying, Appl. Catal. B Environ., 2006, 68(1-2), p 74-84, doi:10.1016/j.apcatb.2006.07.009.

3. A.A. Ismail and D.W. Bahnemann, Photochemical Splitting of Water for Hydrogen Production by Photocatalysis: A Review, Sol. Energy Mater. Sol. Cells, 2014, 128, p 85-101, doi:10.1016/j.solmat.2014.04.037.

4. M. Gardon, C. Fernández-Rodríguez, D. Garzón Sousa, J.M. Doña-Rodríguez, S. Dosta, I.G. Cano, and J.M. Guilemany, Photocatalytic Activity of Nanostructured Anatase Coatings Obtained by Cold Gas Spray, J. Therm. Spray Technol., 2014, 23(7), p 1135-1141, doi:10.1007/s11666-014-0087-0.

5. A. Di Mauro, M.E. Fragalà, V. Privitera, and G. Impellizzeri, ZnO for Application in Photocatalysis: From Thin Films to Nanostructures, Mater. Sci. Semicond. Process., 2017, 69, p 44-51, doi:10.1016/j.mssp.2017.03.029.

6. J. Fang, H. Fan, Y. Ma, Z. Wang, and Q. Chang, Surface Defects Control for ZnO Nanorods Synthesized by Quenching and Their Anti-Recombination in Photocatalysis, Appl. Surf. Sci., 2015, 332, p 47-54, doi:10.1016/j.apsusc.2015.01.139.

7. X. Chen, L. Liu, P.Y. Yu, and S.S. Mao, Increasing Solar Absorption for Photocatalysis with Black Hydrogenated Titanium Dioxide Nanocrystals, 
Science, 2011, 331(6018), p 746-750, doi:10.1126/science.1200448.

8. X. Xi, C. Yang, H. Cao, Z. Yu, J. Li, S. Lin, Z. Ma, and L. Zhao, GaN Nanocolumns Fabricated by Self-Assembly Ni Mask and Its Enhanced Photocatalytic Performance in Water Splitting, Appl. Surf. Sci., 2018, 462, p 310-315, doi:10.1016/j.apsusc.2018.08.113.

9. D. Beydoun, R. Amal, G. Low, and S. McEvoy, Role of Nanoparticles in Photocatalysis, J. Nanopart. Res., 1999, p 439-458, doi: 10.1023/A:1010044830871.

10. A. Sanchez-Martinez, C. Koop-Santa, O. Ceballos-Sanchez, E.R. López-Mena, M.A. González, V. Rangel-Cobián, E. Orozco-Guareño, and M. GarcíaGuaderrama, Study of the Preparation of $\mathrm{TiO}_{2}$ Powder by Different Synthesis Methods, Mater. Res. Express, 2019, 6(8), p 085085(1-13), doi:10.1088/20531591/ab21e8:

11. S. Fan, B. AlOtaibi, S.Y. Woo, Y. Wang, G.A. Botton, and Z. Mi, High Efficiency Solar-to-Hydrogen Conversion on a Monolithically Integrated InGaN/GaN/Si Adaptive Tunnel Junction Photocathode, Nano Lett., 2015, 15(4), p 2721-2726, doi:10.1021/acs.nanolett.5b00535.

12. T. Kida, Y. Minami, G. Guan, M. Nagano, M. Akiyama, and A. Yoshida, Photocatalytic Activity of Gallium Nitride for Producing Hydrogen from Water under Light Irradiation, J. Mater. Sci., 2006, 41(11), p 3527-3534, doi:10.1007/s10853-005-5655-8.

13. J.L. Yang, S.J. An, W. Il Park, G.-C. Yi, and W. Choi, Photocatalysis Using ZnO Thin Films and Nanoneedles Grown by Metal-Organic Chemical Vapor Deposition, Adv. Mater., 2004, 16(18), p 1661-1664, 
doi:10.1002/adma.200306673.

14. Y. Xie and C. Yuan, Transparent $\mathrm{TiO}_{2}$ Sol Nanocrystallites Mediated Homogeneous-like Photocatalytic Reaction and Hydrosol Recycling Process, $J$. Mater. Sci., 2005, 40(24), p 6375-6383, doi:10.1007/s10853-005-1825-y.

15. H.S. Jung, Y.J. Hong, Y. Li, J. Cho, Y.J. Kim, and G.C. Yi, Photocatalysis Using GaN Nanowires, ACS Nano, 2008, 2(4), p 637-642, doi:10.1021/nn700320y.

16. G.J. Yang, C.J. Li, F. Han, W.Y. Li, and A. Ohmori, Low Temperature Deposition and Characterization of $\mathrm{TiO}_{2}$ Photocatalytic Film through Cold Spray, Appl. Surf. Sci., 2008, 254(3), p 3979-3982, doi:10.1016/j.apsusc.2007.12.016.

17. A.E. Wickenden, D.D. Koleske, R.L. Henry, M.E. Twigg, and M. Fatemi, Resistivity Control in Unintentionally Doped GaN Films Grown by MOCVD, $J$. Cryst. Growth, 2004, 260(1-2), p 54-62, doi:10.1016/j.jcrysgro.2003.08.024.

18. T.D. Moustakas, E. Iliopoulos, A.V. Sampath, H.M. Ng, D. Doppalapudi, M. Misra, D. Korakakis, and R. Singh, Growth and Device Applications of IIINitrides by MBE, J. Cryst. Growth, 2001, 227-228, p 13-20, doi:10.1016/S0022-0248(01)00625-X.

19. H. Geng, H. Sunakawa, N. Sumi, K. Yamamoto, A. Atsushi Yamaguchi, and A. Usui, Growth and Strain Characterization of High Quality GaN Crystal by HVPE, J. Cryst. Growth, 2012, 350(1), p 44-49, doi:10.1016/j.jcrysgro.2011.12.020.

20. M. Bideau, B. Claudel, C. Dubien, L. Faure, and H. Kazouan, On the 'Immobilization' of Titanium Dioxide in the Photocatalytic Oxidation of Spent Waters, Appl. Surf. Sci., 2008, 254(3), p 3979-3982, doi:10.1016/j.apsusc.2007.12.016. 
21. N.J. Peill and M.R. Hoffmann, Development and Optimization of a $\mathrm{TiO}_{2}$-Coated Fiber-Optic Cable Reactor: Photocatalytic Degradation of 4-Chlorophenol, Environ. Sci. Technol., 1995, 29(12), p 2974-2981, doi:10.1021/es00012a013.

22. H. Hajipour, A. Abdollah-zadeh, H. Assadi, E. Taheri-Nassaj, and H. Jahed, Effect of Feedstock Powder Morphology on Cold-Sprayed Titanium Dioxide Coatings, J. Therm. Spray Technol., 2018, 27(8), p 1542-1550, doi:10.1007/s11666-018-0782-3.

23. K. Ravi, Y. Ichikawa, T. Deplancke, K. Ogawa, O. Lame, and J.Y. Cavaille, Development of Ultra-High Molecular Weight Polyethylene (UHMWPE) Coating by Cold Spray Technique, J. Therm. Spray Technol., 2015, 24(6), p $1015-1025$.

24. X. Chu, H. Che, P. Vo, R. Chakrabarty, B. Sun, J. Song, and S. Yue, Understanding the Cold Spray Deposition Efficiencies of $316 \mathrm{~L} / \mathrm{Fe}$ Mixed Powders by Performing Splat Tests onto as-Polished Coatings, Surf. Coat. Technol., 2017, 324, p 353-360, doi: 10.1016/j.surfcoat.2017.05.083.

25. H.Y. Lee, S.H. Jung, S.Y. Lee, Y.H. You, and K.H. Ko, Correlation between $\mathrm{Al}_{2} \mathrm{O}_{3}$ Particles and Interface of $\mathrm{Al}-\mathrm{Al}_{2} \mathrm{O}_{3}$ Coatings by Cold Spray, Appl. Surf. Sci., Elsevier, 2005, 252(5), p 1891-1898.

26. K. Ravi, W.L. Sulen, C. Bernard, Y. Ichikawa, and K. Ogawa, Fabrication of Micro-/Nano-Structured Super-Hydrophobic Fluorinated Polymer Coatings by Cold-Spray, Surf. Coatings Technol., Elsevier, 2019, 373(May), p 17-24, doi:10.1016/j.surfcoat.2019.05.078.

27. H.X. Hu, S.L. Jiang, Y.S. Tao, T.Y. Xiong, and Y.G. Zheng, Cavitation Erosion and Jet Impingement Erosion Mechanism of Cold Sprayed $\mathrm{Ni}-\mathrm{Al}_{2} \mathrm{O}_{3}$ Coating, 
Nucl. Eng. Des., 2011, 241(12), p 4929-4937.

28. T.H. Van Steenkiste, J.R. Smith, and R.E. Teets, Aluminum Coatings via Kinetic Spray with Relatively Large Powder Particles, Surf. Coat. Technol., 2002, 154(23), p 237-252, doi:10.1016/S0257-8972(02)00018-X.

29. D. Hanft, J. Exner, M. Schubert, T. Stöcker, P. Fuierer, and R. Moos, An Overview of the Aerosol Deposition Method: Process Fundamentals and New Trends in Materials Applications, J. Ceram. Sci. Technol., 2015, 6(3), p 147-181, doi: $\underline{10.4416 / J C S T 2015-00018}$.

30. W. Lock Sulen, K. Ravi, C. Bernard, Y. Ichikawa, and K. Ogawa, Deposition Mechanism Analysis of Cold-Sprayed Fluoropolymer Coatings and Its Wettability Evaluation, J. Therm. Spray Technol., 2020, doi:10.1007/s11666020-01059-w.

31. Y. Ichikawa and K. Ogawa, Effect of Substrate Surface Oxide Film Thickness on Deposition Behavior and Deposition Efficiency in the Cold Spray Process, $J$. Therm. Spray Technol., 2015, 24(7), p 1269-1276, doi:10.1007/s11666-0150299-y.

32. N.I. Omar, S. Selvami, M. Kaisho, M. Yamada, T. Yasui, and M. Fukumoto, Deposition of Titanium Dioxide Coating by the Cold-Spray Process on Annealed Stainless Steel Substrate, Coatings, 2020, 10(10), p 1-13.

33. J. Wang, Y. Asakura, and S. Yin, Preparation of $\left(\mathrm{Zn}_{1+\mathrm{X}} \mathrm{Ge}\right)\left(\mathrm{N}_{2} \mathrm{O}_{\mathrm{x}}\right)$ Nanoparticles with Enhanced $\mathrm{NO}_{\mathrm{x}}$ Decomposition Activity under Visible Light Irradiation by Nitridation of $\mathrm{Zn}_{2} \mathrm{GeO}_{4}$ Nanoparticles Designed Precisely, Nanoscale, 2019, 11(42), p 20151-20160, doi:10.1039/C9NR05244E.

34. S. Yin, Q. Zhang, F. Saito, and T. Sato, Preparation of Visible Light-Activated 
Titania Photocatalyst by Mechanochemical Method, Chem. Lett., 2003, 32(4), p 358-359, doi:10.1246/cl.2003.358.

35. R. Ghelichi, S. Bagherifard, D. MacDonald, I. Fernandez-Pariente, B. Jodoin, and M. Guagliano, Experimental and Numerical Study of Residual Stress Evolution in Cold Spray Coating, Appl. Surf. Sci., 2014, 288, p 26-33, doi:10.1016/j.apsusc.2013.09.074.

36. S.I. Imbriglio, M. Hassani-Gangaraj, D. Veysset, M. Aghasibeig, R. Gauvin, K.A. Nelson, C.A. Schuh, and R.R. Chromik, Adhesion Strength of Titanium Particles to Alumina Substrates: A Combined Cold Spray and LIPIT Study, Surf. Coatings Technol., Elsevier B.V., 2019, 361, p 403-412.

37. A. Banerjee, D. Bernoulli, H. Zhang, M.F. Yuen, J. Liu, J. Dong, F. Ding, J. Lu, M. Dao, W. Zhang, Y. Lu, and S. Suresh, Ultralarge Elastic Deformation of Nanoscale Diamond, Science (80-. )., American Association for the Advancement of Science, 2018, 360(6386), p 300-302.

38. H. Zhang, J. Tersoff, S. Xu, H. Chen, Q. Zhang, K. Zhang, Y. Yang, C.S. Lee, K.N. Tu, J. Li, and Y. Lu, Approaching the Ideal Elastic Strain Limit in Silicon Nanowires, Sci. Adv., American Association for the Advancement of Science, 2016, 2(8).

39. A. Nie, Y. Bu, J. Huang, Y. Shao, Y. Zhang, W. Hu, J. Liu, Y. Wang, B. Xu, Z. Liu, H. Wang, W. Yang, and Y. Tian, Direct Observation of Room-Temperature Dislocation Plasticity in Diamond, Matter, Cell Press, 2020, 2(5), p 1222-1232.

40. S. Fan, X. Li, R. Fan, and Y. Lu, Size-Dependent Fracture Behavior of GaN Pillars under Room Temperature Compression, Nanoscale, Royal Society of Chemistry, 2020, 12(45), p 23241-23247. 
41. M.T. Puth, M. Neuhäuser, and G.D. Ruxton, Effective Use of Pearson's ProductMoment Correlation Coefficient, Anim. Behav., 2014, 93, p 183-189, doi:10.1016/j.anbehav.2014.05.003.

42. P.C. King, S.H. Zahiri, and M. Jahedi, Focused Ion Beam Micro-Dissection of Cold-Sprayed Particles, Acta Mater., 2008, 56(19), p 5617-5626, doi:10.1016/j.actamat.2008.07.034.

43. M. Zhang, Y. Liu, M. Yang, W. Zhang, J. Zhou, Z. Zhang, E. Xie, X. Pan, and S. Li, High Performance Self-Powered Ultraviolet Photodetectors Based on Electrospun Gallium Nitride Nanowires, Appl. Surf. Sci., 2018, 452, p 43-48, doi:10.1016/j.apsusc.2018.04.225.

44. D. Nath, F. Singh, and R. Das, X-Ray Diffraction Analysis by Williamson-Hall, Halder-Wagner and Size-Strain Plot Methods of CdSe Nanoparticles- a Comparative Study, Mater. Chem. Phys., 2020, 239, p 122021, doi:10.1016/j.matchemphys.2019.122021.

45. A.W. Burton, K. Ong, T. Rea, and I.Y. Chan, On the Estimation of Average Crystallite Size of Zeolites from the Scherrer Equation: A Critical Evaluation of Its Application to Zeolites with One-Dimensional Pore Systems, Microporous Mesoporous $\quad$ Mater., $\quad 2009, \quad$ 117(1-2), $\quad \mathrm{p} \quad$ 75-90, doi:10.1016/j.micromeso.2008.06.010.

46. V. Mote, Y. Purushotham, and B. Dole, Williamson-Hall Analysis in Estimation of Lattice Strain in Nanometer-Sized ZnO Particles, J. Theor. Appl. Phys., 2012, 6(1), p 6-14, doi:10.1186/2251-7235-6-6.

47. G.K. Williamson and W.H. Hall, X-Ray Broadening from Filed Aluminium andWolfram, Acta Metall., 1953, 1(1), p 22-31, doi: 10.1016/0001- 
$\underline{6160(53) 90006-6 .}$

48. P.M. Kibasomba, S. Dhlamini, M. Maaza, C.P. Liu, M.M. Rashad, D.A. Rayan, and B.W. Mwakikunga, Strain and Grain Size of $\mathrm{TiO}_{2}$ Nanoparticles from TEM, Raman Spectroscopy and XRD: The Revisiting of the Williamson-Hall Plot Method, Results Phys., Elsevier B.V., 2018, 9, p 628-635.

49. M. Yamada, H. Isago, H. Nakano, and M. Fukumoto, Cold Spraying of $\mathrm{TiO}_{2}$ Photocatalyst Coating with Nitrogen Process Gas, J. Therm. Spray Technol., 2010, 19(6), p 1218-1223, doi:10.1007/s11666-010-9520-1. 


\section{Figure Captions:}

Fig. 1 Schematic representation of a typical downstream injection cold spray system.

Fig. 2 Back scattered electron (BSE) observation protocol used to evaluate the relative deposition behavior of the GaN particles on the stainless steel substrate. For the halfwidth of the spray area $(3 \mathrm{~mm}), 16 \mathrm{BSE}$ micrographs were taken at a magnification of $\times 500$. For each of these BSE micrographs, higher magnification $(\times 2500)$ BSE images were taken at their centers.

Fig. 3 Schematic diagram of the NOx decomposition test.

Fig. 4 SEM images of the GaN feedstock: (a) nano-sized particles (average sectional area: $0.026 \mu \mathrm{m}^{2}$ ), (b) original agglomerated micro-sized particles (average length: 1.97 $\pm 0.013 \mu \mathrm{m}$, width: $0.74 \pm 0.086 \mu \mathrm{m}$ and sectional area: $1.50 \pm 0.045 \mu \mathrm{m}^{2}$ ), and (c) original super agglomerated particle.

Fig. 5 (a) Deposited micro-sized particles (with average sectional area $>10 \mu \mathrm{m}^{2}$ ) at a magnification of $\times 500$, (b) deposited nano-sized particles (with average sectional area between $0.02-10 \mu \mathrm{m}^{2}$ ) at a magnification of $\times 2500$, and (c) evolution of the number of particles deposited as a function of their coverage area and in relation to the surface area of the initial feedstock. The results presented here correspond to a specimen coldsprayed at $25^{\circ} \mathrm{C}$ and $0.6 \mathrm{MPa}$. All the other investigated cold-sprayed conditions exhibited the same tendencies.

Fig. 6 Evolution of the substrate coverage area after splat tests along the half-width of the spray area for the two gas pressures (a) $0.4 \mathrm{MPa}$ (b) $0.6 \mathrm{MPa}$, and the three temperatures. 
Fig. 7 Evolution of the (a)-(b) coverage area, (c)-(d) number of micro-size particles, and (e)-(f) number of nano-sized particles along the half-width of the spray area for the two gas pressures and the three temperatures investigated.

Fig. 8 Evolution of the number of nano-sized particles correlated with the coverage area of substrate along the half-width of the spray area for the two gas pressures (a) $0.4 \mathrm{MPa}$ (b) $0.6 \mathrm{MPa}$, and the three temperatures.

Fig. 9 SEM images of (a) the cross-sectional area of the deposited particles at a tilt angle of $45^{\circ}$, (b) interface between the deposited particles and stainless steel substrate, (c) the topographical morphologies of deposited particles which derived from super agglomerated particles, and (d) topographical morphologies of adjacent deposited particles derived from micro-sized particles.

Fig. 10 Evolution of the average coating thickness by SEM images under each spray condition (two gas pressures and three temperatures).

Fig. 11 Deposition efficiency of the GaN coatings under the spray condition in two gas pressures and two temperatures.

Fig. 12 XRD spectra of the GaN powder, GaN coatings and stainless steel substrate.

Fig. 13 Evolution of the Williamson-Hall plot for the coatings and GaN powder.

Fig. 14 Photocatalytic properties of each cold-sprayed specimen and GaN powder evaluated by NOx decomposition tests.

Fig. 15 Evolution of the deNOx ratio with the (a) thickness and (b) roughness of the coatings. 
Table 1 Material properties of GaN powder and stainless steel substrates.

\begin{tabular}{cccc}
\hline \multicolumn{4}{c}{ GaN } \\
\hline Parameter & Density & Melting temperature & Band gap \\
& $(\mathrm{g} / \mathrm{cm} 3)$ & $(\mathrm{K})$ & $(\mathrm{eV})$ \\
Value & 0.7 & $>1600$ & 3.4 \\
\hline Parameter & Stainless steel substrate & Hardness \\
& $(\mu \mathrm{m})$ & Roughness, Rz & $($ HV) \\
As-received & $0.10 \pm 0.012$ & $0.83 \pm 0.076$ & 216 \\
Mirror polishing & $0.06 \pm 0.012$ & $0.39 \pm 0.101$ & \\
\hline
\end{tabular}


Table 2 Cold spray parameters for splat and multi-pass tests.

\begin{tabular}{ll}
\hline Parameter & Values \\
\hline Gas type & Compressed air \\
Powder feeding rate $(\mathrm{g} / \mathrm{s})$ & 0.019 \\
Gas pressure $(\mathrm{MPa})$ & $0.4,0.6$ \\
Gas temperature $\left({ }^{\circ} \mathrm{C}\right)$ & $\mathrm{RT}, 300,400$ \\
Traverse speed, $\mathrm{TS}(\mathrm{mm} / \mathrm{s})$ & 20.0 \\
Stand-off distance, $\mathrm{SoD}(\mathrm{mm})$ & 20.0 \\
Pass number & 1,16 \\
\hline
\end{tabular}


Table 3 Evolution of $r^{2}$ (coefficient of determination) under each spray condition.

\begin{tabular}{cccc}
\hline Conditions & $\begin{array}{c}\mathrm{r}^{2} \text { for substrate } \\
\text { coverage area }\end{array}$ & $\begin{array}{c}\mathrm{r}^{2} \text { for number of } \\
\text { micro-sized particles }\end{array}$ & $\begin{array}{c}\mathrm{r}^{2} \text { for number of } \\
\text { nano-sized particles }\end{array}$ \\
\hline $25^{\circ} \mathrm{C}$ and $0.4 \mathrm{MPa}$ & 0.94 & 0.87 & 0.97 \\
$25{ }^{\circ} \mathrm{C}$ and $0.6 \mathrm{MPa}$ & 0.87 & 0.76 & 0.94 \\
$300{ }^{\circ} \mathrm{C}$ and $0.4 \mathrm{MPa}$ & 0.91 & 0.83 & 0.96 \\
$300{ }^{\circ} \mathrm{C}$ and $0.6 \mathrm{MPa}$ & 0.92 & 0.84 & 0.99 \\
$400{ }^{\circ} \mathrm{C}$ and $0.4 \mathrm{MPa}$ & 0.95 & 0.86 & 0.99 \\
$400{ }^{\circ} \mathrm{C}$ and $0.6 \mathrm{MPa}$ & 0.96 & 0.89 & 0.99 \\
\hline
\end{tabular}


Table 4 Roughness and thickness of each coating under different spray conditions.

\begin{tabular}{ccccccc}
\hline & $\begin{array}{c}\text { Feedstock } \\
\text { type }\end{array}$ & $\begin{array}{c}\text { Spray } \\
\text { temperature }\end{array}$ & $\begin{array}{c}\text { Spray } \\
\text { pressure }\end{array}$ & $\begin{array}{c}\text { Spray pass } \\
\text { number }\end{array}$ & $\begin{array}{c}\text { Roughness, } \\
\text { Ra }(\mu \mathrm{m})\end{array}$ & $\begin{array}{c}\text { Thickness } \\
(\mu \mathrm{m})\end{array}$ \\
\hline $\mathrm{G} 1$ & $\mathrm{GaN}$ & $300^{\circ} \mathrm{C}$ & $0.4 \mathrm{MPa}$ & 16 & 2.15 & 6.9 \\
$\mathrm{G} 2$ & $\mathrm{GaN}$ & $300{ }^{\circ} \mathrm{C}$ & $0.6 \mathrm{MPa}$ & 16 & 4.16 & 7.8 \\
$\mathrm{G} 3$ & $\mathrm{GaN}$ & $400{ }^{\circ} \mathrm{C}$ & $0.4 \mathrm{MPa}$ & 16 & 2.82 & 9.4 \\
$\mathrm{G} 4$ & $\mathrm{GaN}$ & $400{ }^{\circ} \mathrm{C}$ & $0.6 \mathrm{MPa}$ & 16 & 5.47 & 10.4 \\
\hline
\end{tabular}


Table 5 Evolution of the strain and average crystallite size of each specimen.

\begin{tabular}{lccccc}
\hline & G1 & G2 & G3 & G4 & GaN powder \\
\hline Strain $\left(\times 10^{-3}\right)$ & 3.0 & 1.7 & 1.5 & 2.8 & 0.2 \\
\hline Crystallite size D $(\mathrm{nm})$ & 22.7 & 18.2 & 18.8 & 18.3 & 19.9 \\
\hline
\end{tabular}




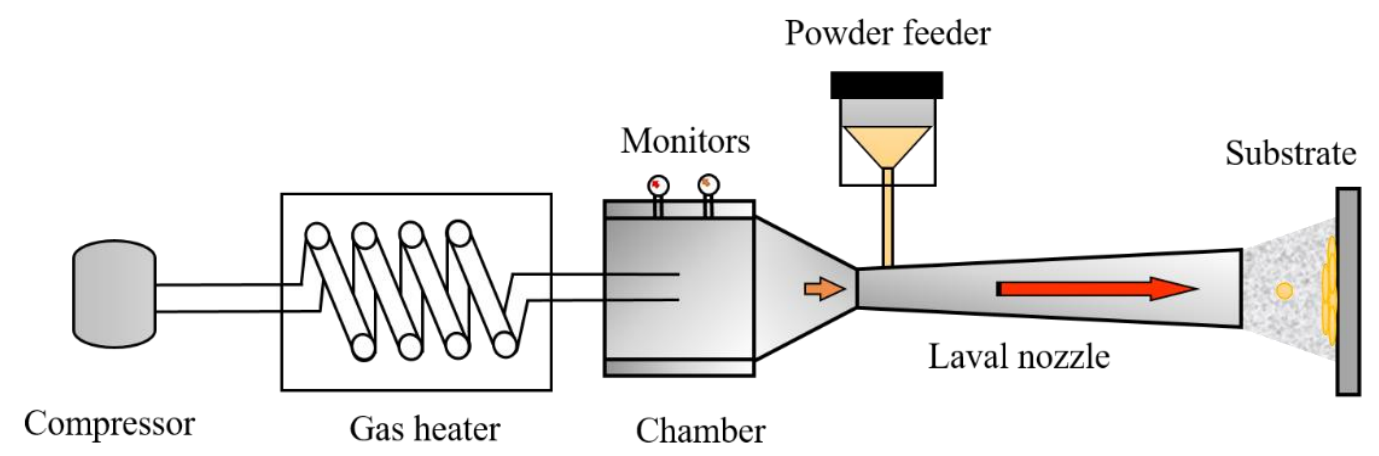

Fig. 1 Schematic representation of a typical downstream injection cold spray system. 


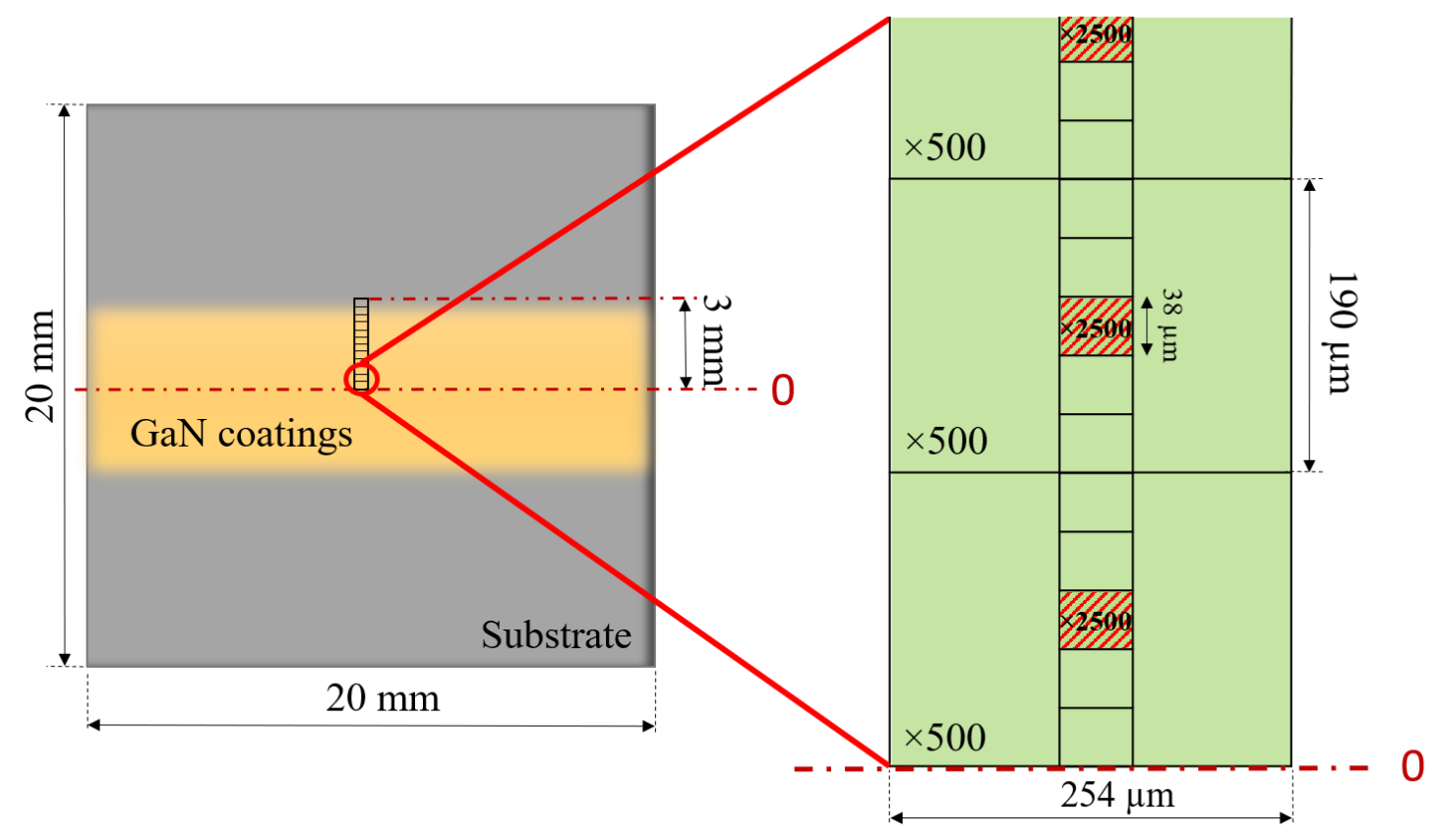

Fig. 2 Back scattered electron (BSE) observation protocol used to evaluate the relative deposition behavior of the GaN particles on the stainless steel substrate. For the half-width of the spray area $(3 \mathrm{~mm}), 16$ BSE micrographs were taken at a magnification of $\times 500$. For each of these BSE micrographs, higher magnification $(\times 2500)$ BSE images were taken at their centers. 


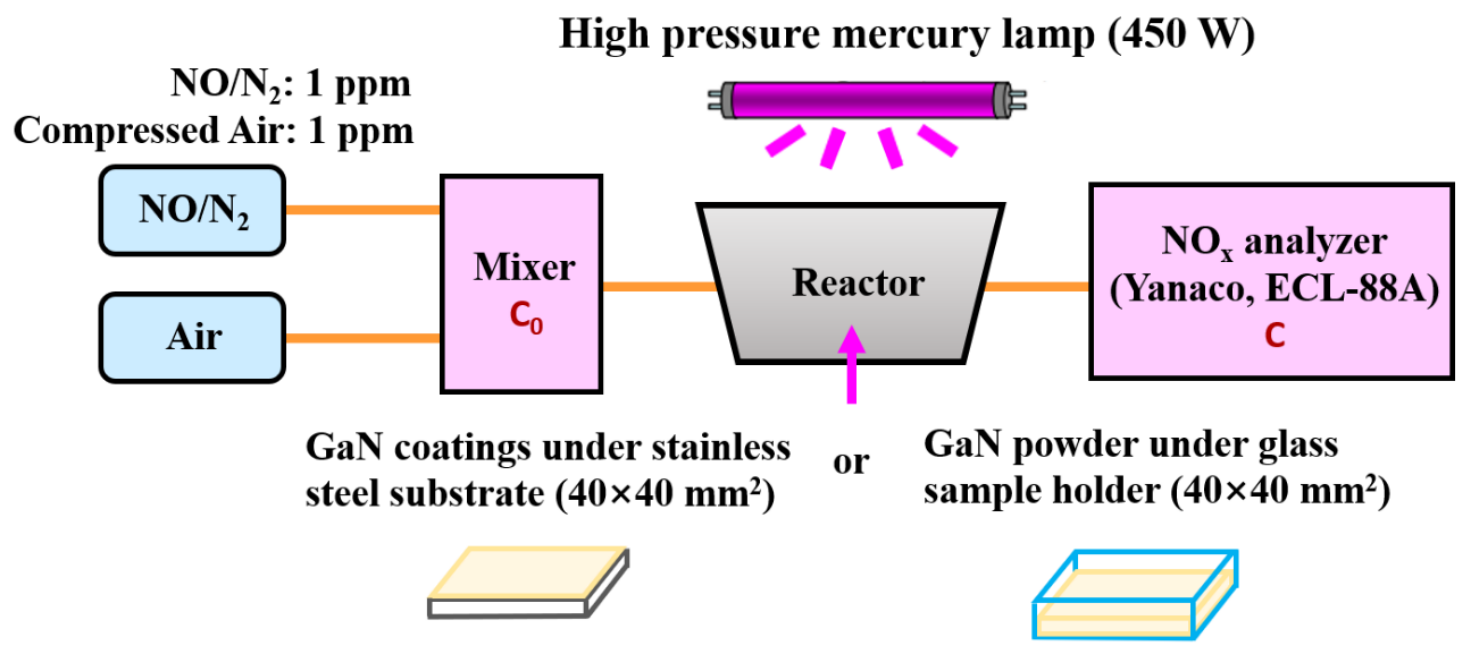

Fig. 3 Schematic diagram of the NOx decomposition test. 

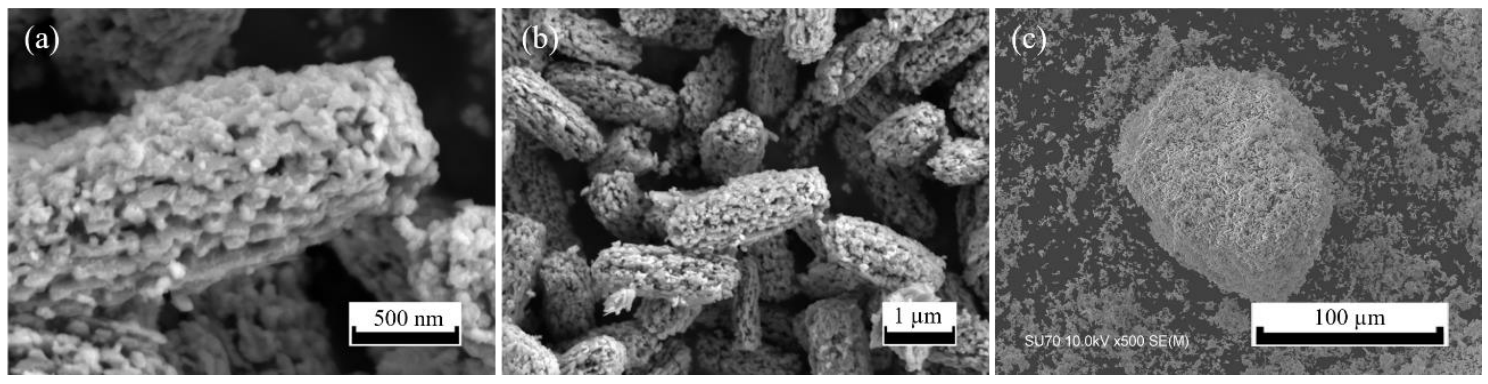

Fig. 4 SEM images of the GaN feedstock: (a) nano-sized particles (average sectional area: $0.026 \mu \mathrm{m}^{2}$ ), (b) original agglomerated micro-sized particles (average length: $1.97 \pm 0.013 \mu \mathrm{m}$, width: $0.74 \pm 0.086 \mu \mathrm{m}$ and sectional area: $1.50 \pm 0.045 \mu \mathrm{m}^{2}$ ), and (c) original super agglomerated particle. 

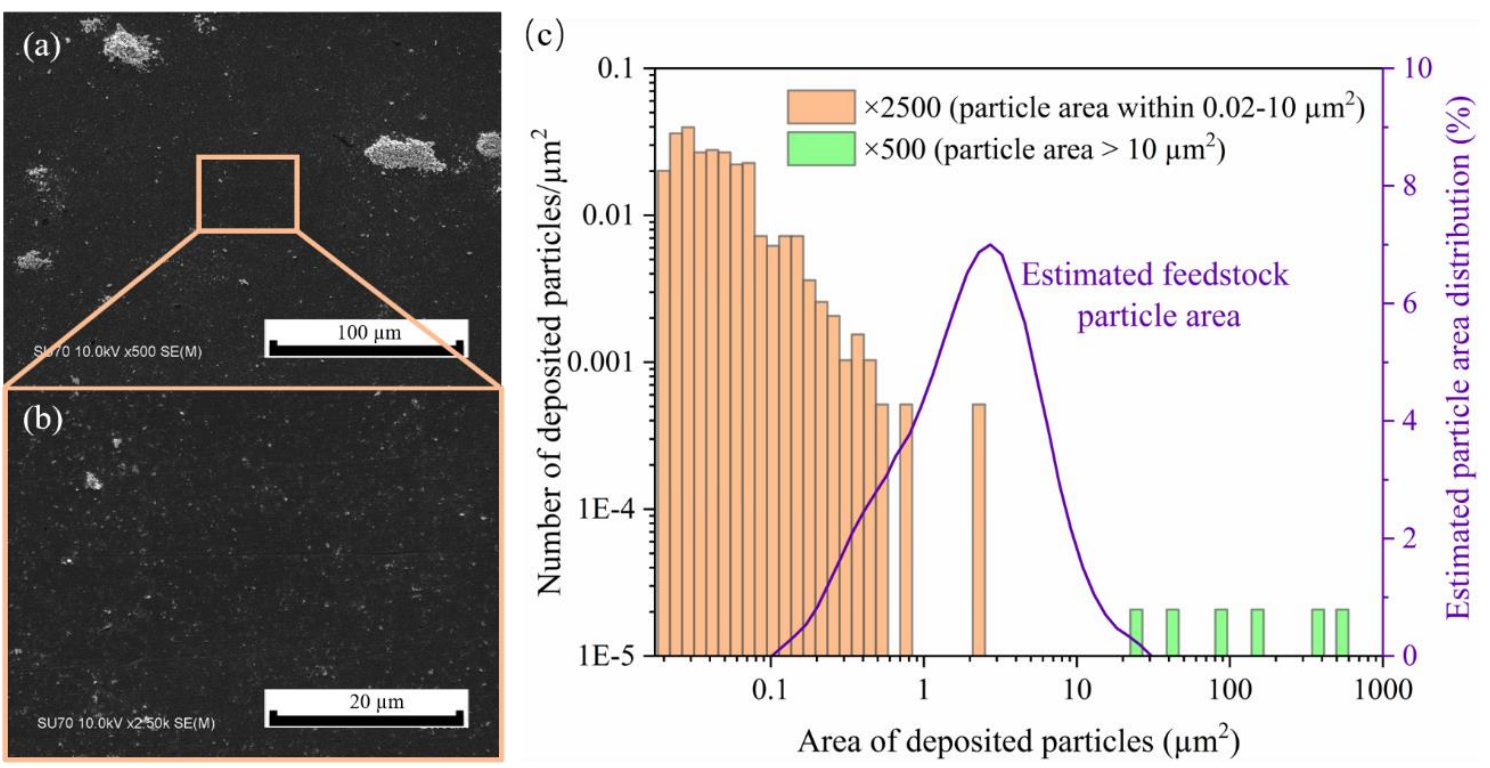

Fig. 5 (a) Deposited micro-sized particles (with average sectional area $>10 \mu \mathrm{m}^{2}$ ) at a magnification of $\times 500$, (b) deposited nano-sized particles (with average sectional area between $0.02-10 \mu \mathrm{m}^{2}$ ) at a magnification of $\times 2500$, and (c) evolution of the number of particles deposited as a function of their coverage area and in relation to the surface area of the initial feedstock. The results presented here correspond to a specimen cold-sprayed at $25^{\circ} \mathrm{C}$ and 0.6 MPa. All the other investigated cold-sprayed conditions exhibit the same tendencies. 
(a) $0.4 \mathrm{MPa}$

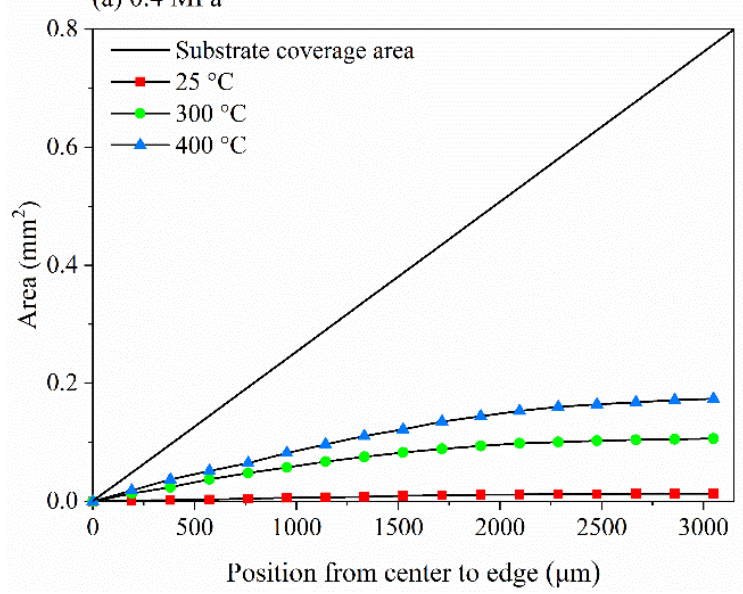

(a) $0.6 \mathrm{MPa}$

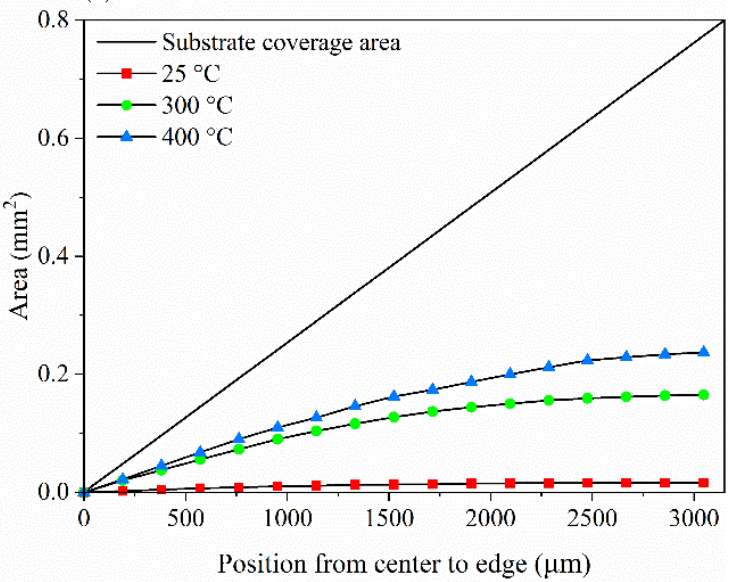

Fig. 6 Evolution of the substrate coverage area after splat tests along the half-width of the spray area for the two gas pressures (a) $0.4 \mathrm{MPa}$ (b) $0.6 \mathrm{MPa}$, and the three temperatures. 
(a) $0.4 \mathrm{MPa}$

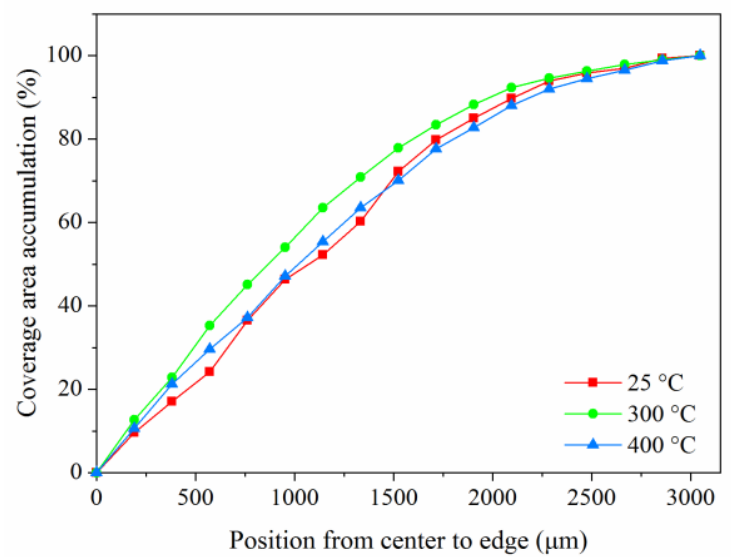

(c) $0.4 \mathrm{MPa}$

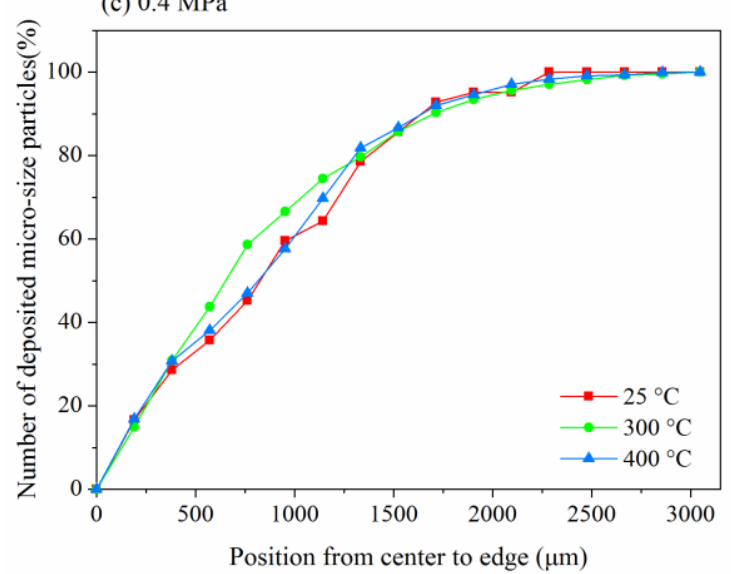

(e) $0.4 \mathrm{MPa}$

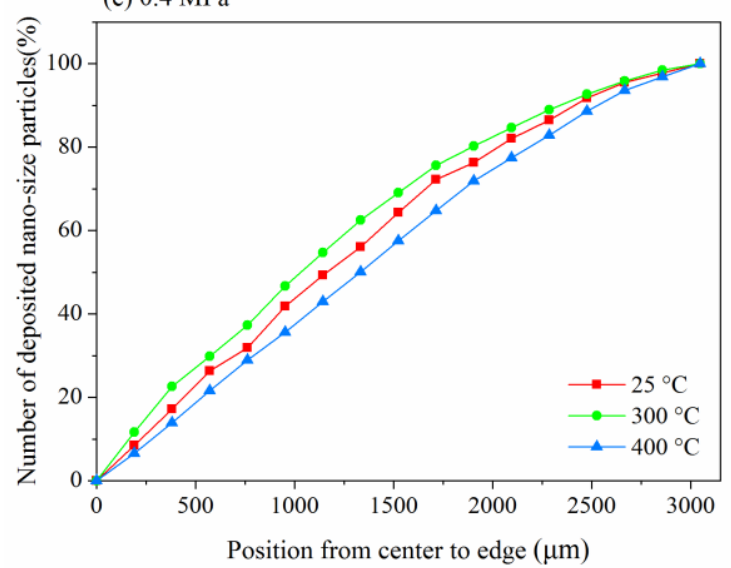

(b) $0.6 \mathrm{MPa}$

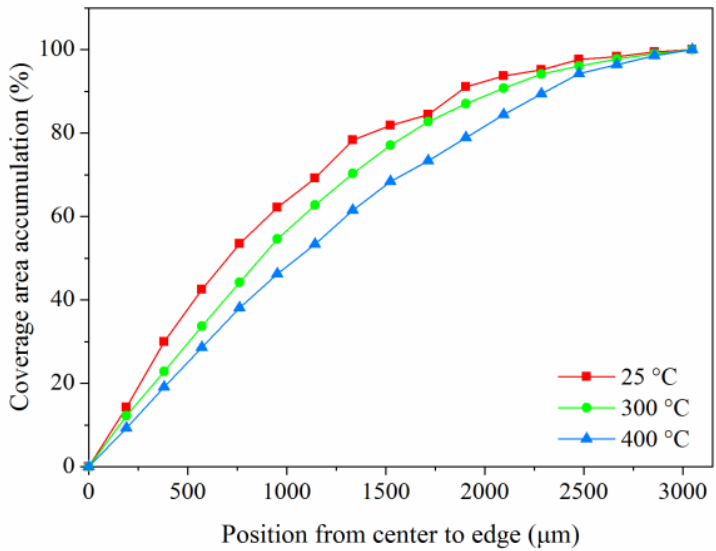

(d) $0.6 \mathrm{MPa}$

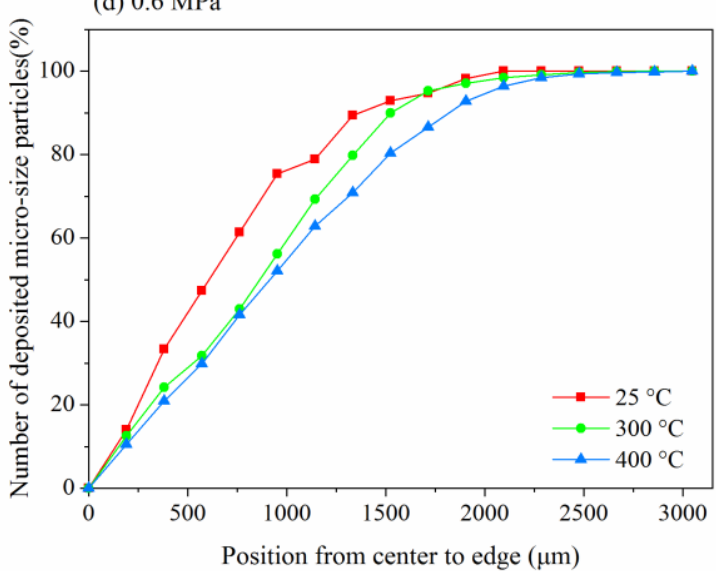

(f) $0.6 \mathrm{MPa}$

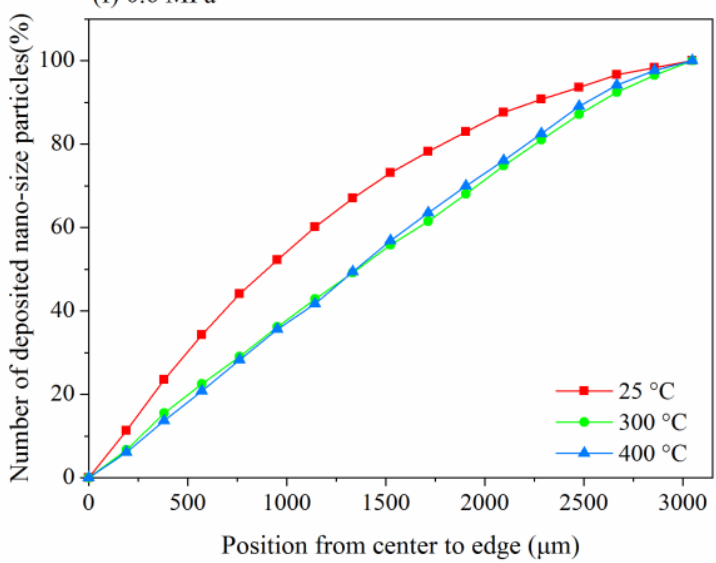

Fig. 7 Evolution of the (a)-(b) coverage area, (c)-(d) number of micro-size particles, and (e)-(f) number of nano-sized particles along the half-width of the spray area for the two gas pressures and the three temperatures investigated. 
(a) $0.4 \mathrm{MPa}$

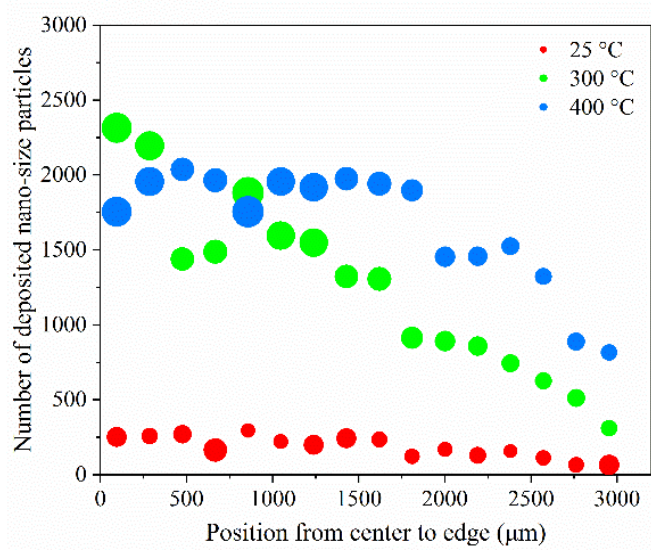

(b) $0.6 \mathrm{MPa}$

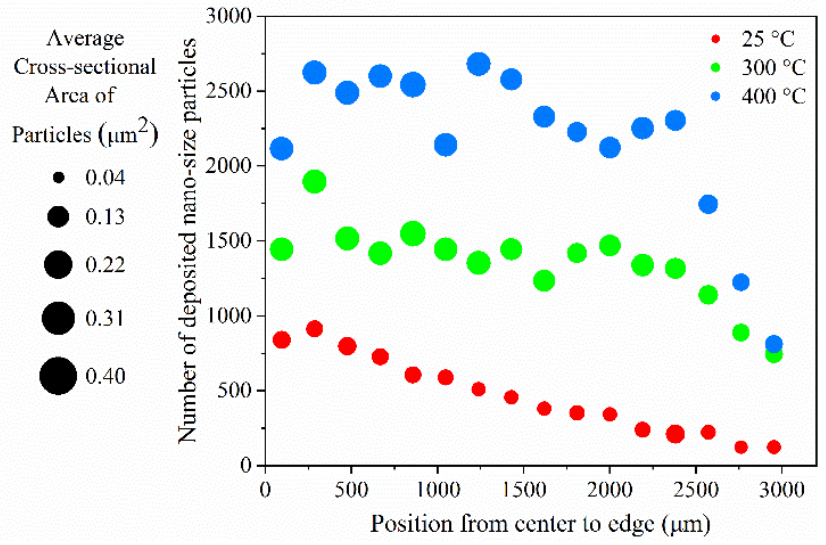

Fig. 8 Evolution of the number of nano-sized particles correlated with the coverage area of substrate along the half-width of the spray area for the two gas pressures (a) $0.4 \mathrm{MPa}$ (b) 0.6 MPa, and the three temperatures. 


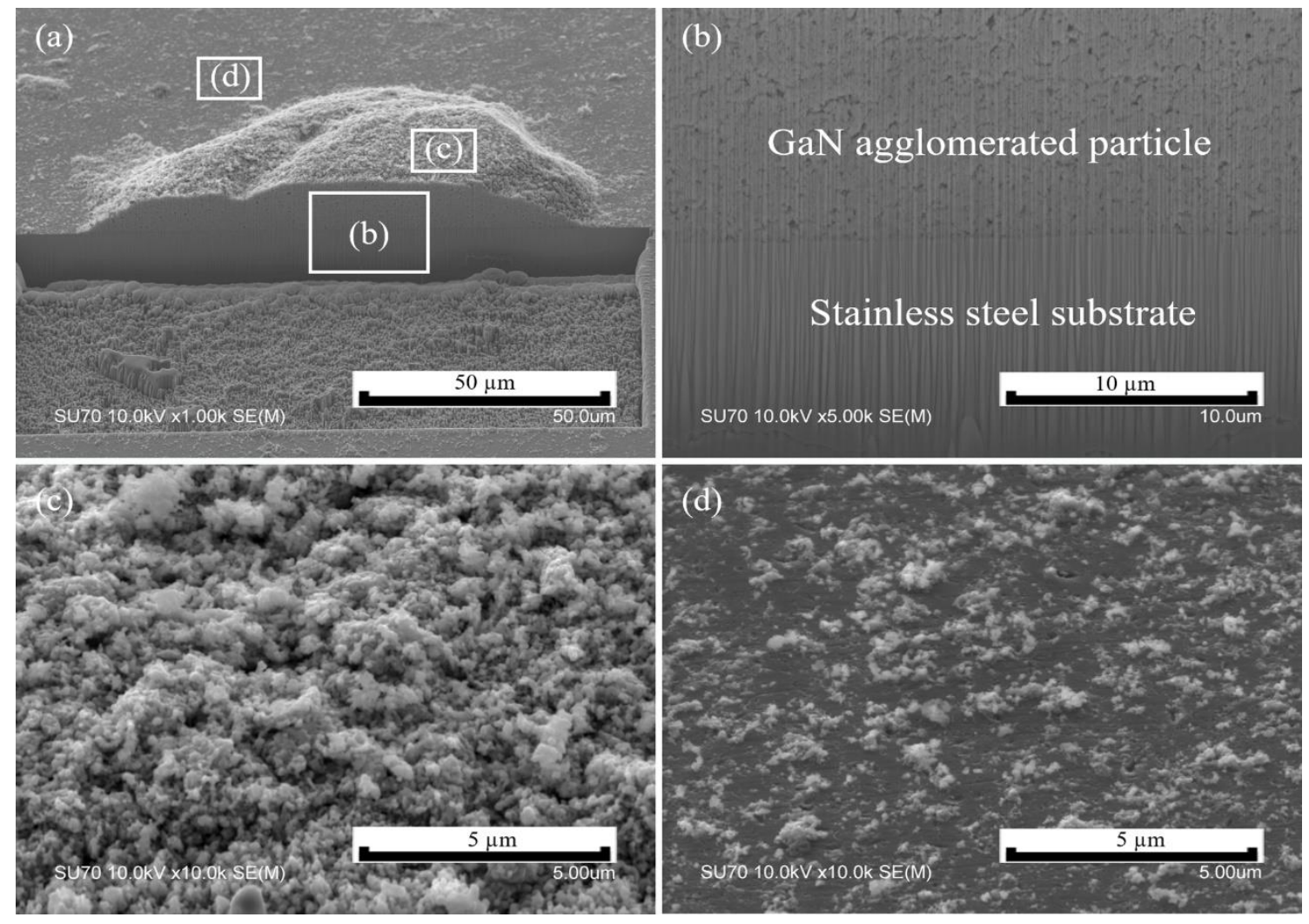

Fig. 9 SEM images of (a) the cross-sectional area of the deposited particles at a tilt angle of $45^{\circ}$,

(b) interface between the deposited particles and stainless steel substrate, (c) the topographical morphologies of deposited particles which derived from super agglomerated particles, and (d) topographical morphologies of adjacent deposited particles derived from micro-sized particles. 


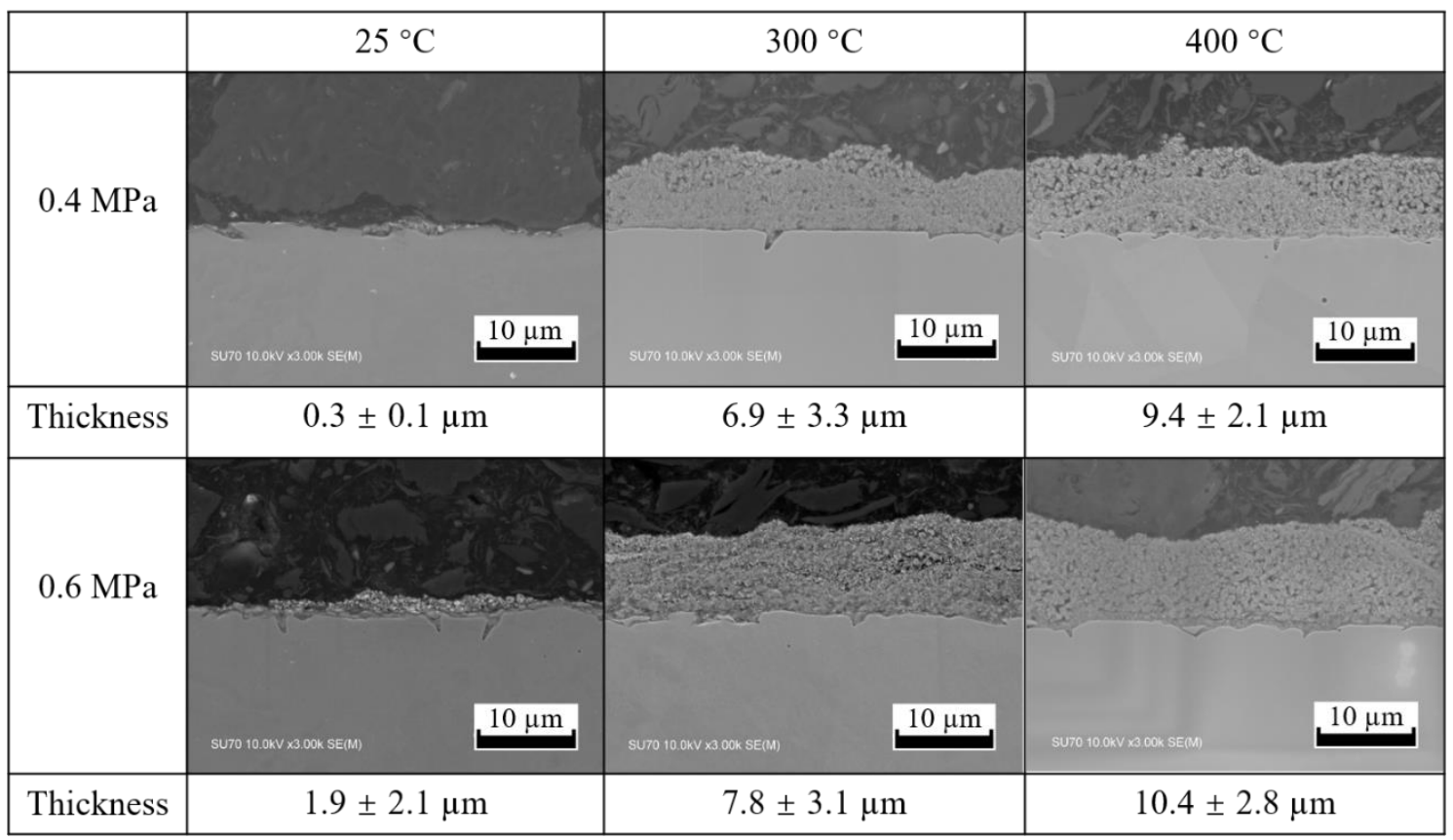

Fig. 10 Evolution of the average coating thickness by SEM images under each spray condition (two gas pressures and three temperatures). 


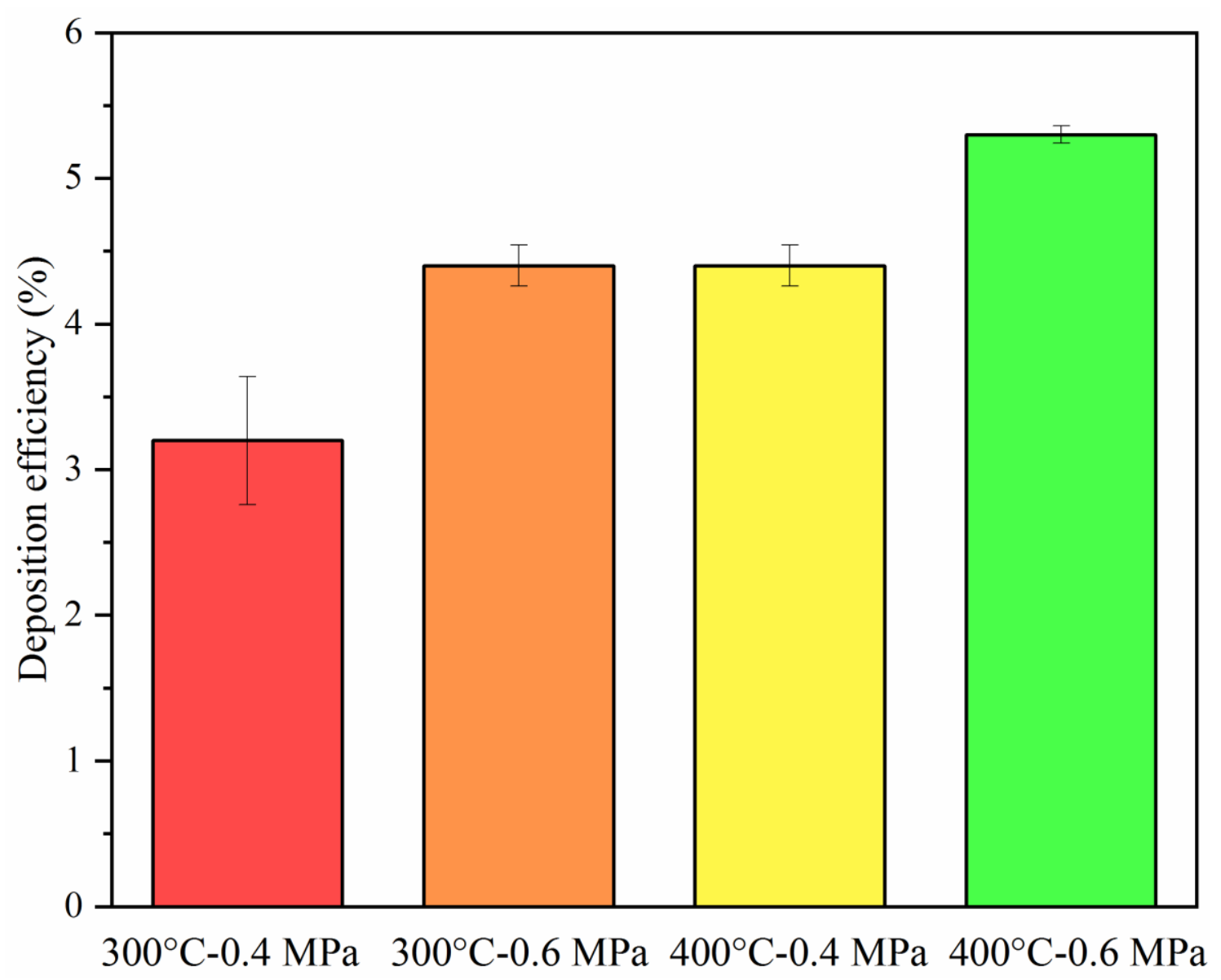

Fig. 11 Deposition efficiency of the GaN coatings under the spray condition in two gas pressures and two temperatures. 


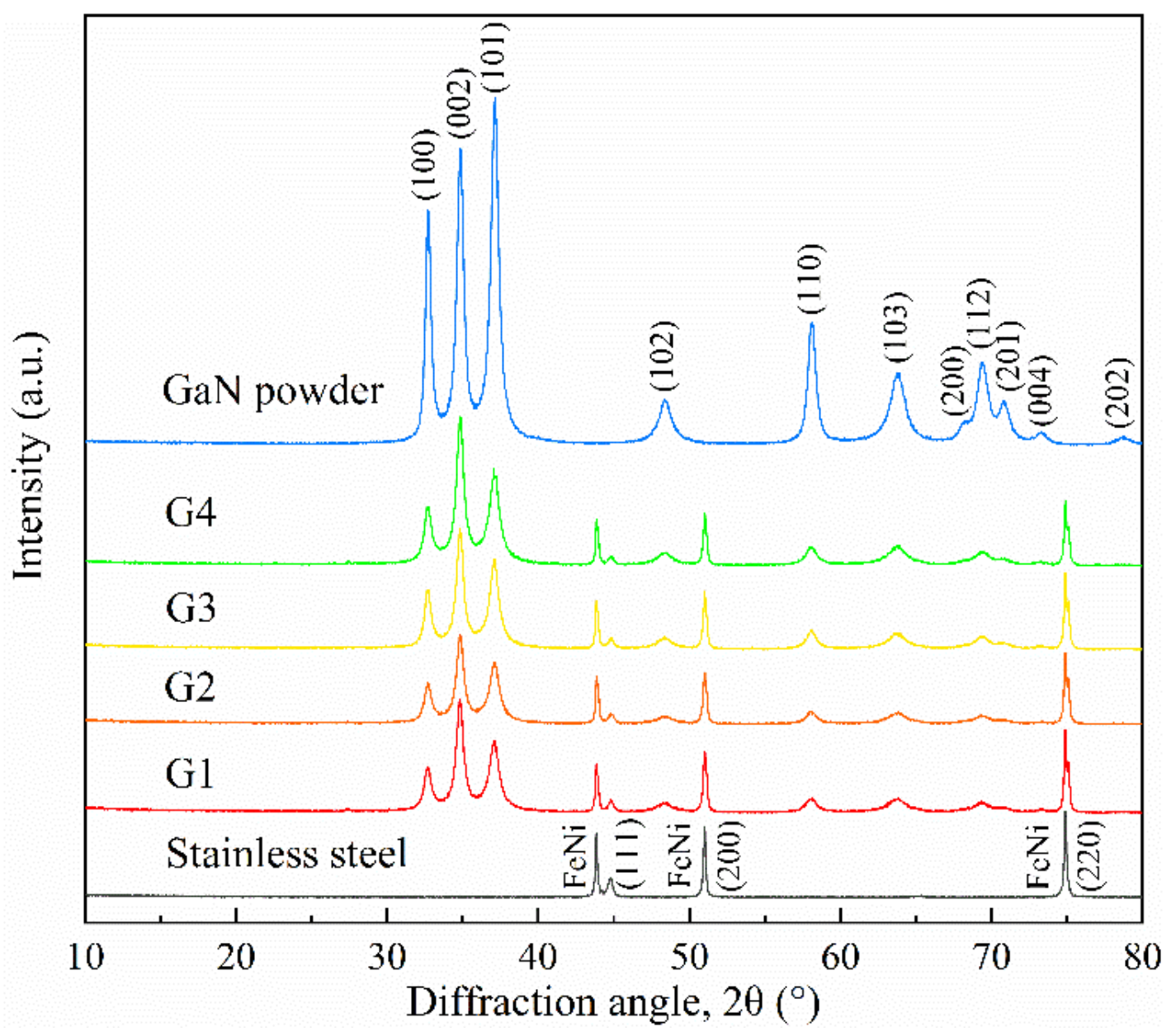

Fig. 12 XRD spectra of the GaN powder, GaN coatings and stainless steel substrate. 


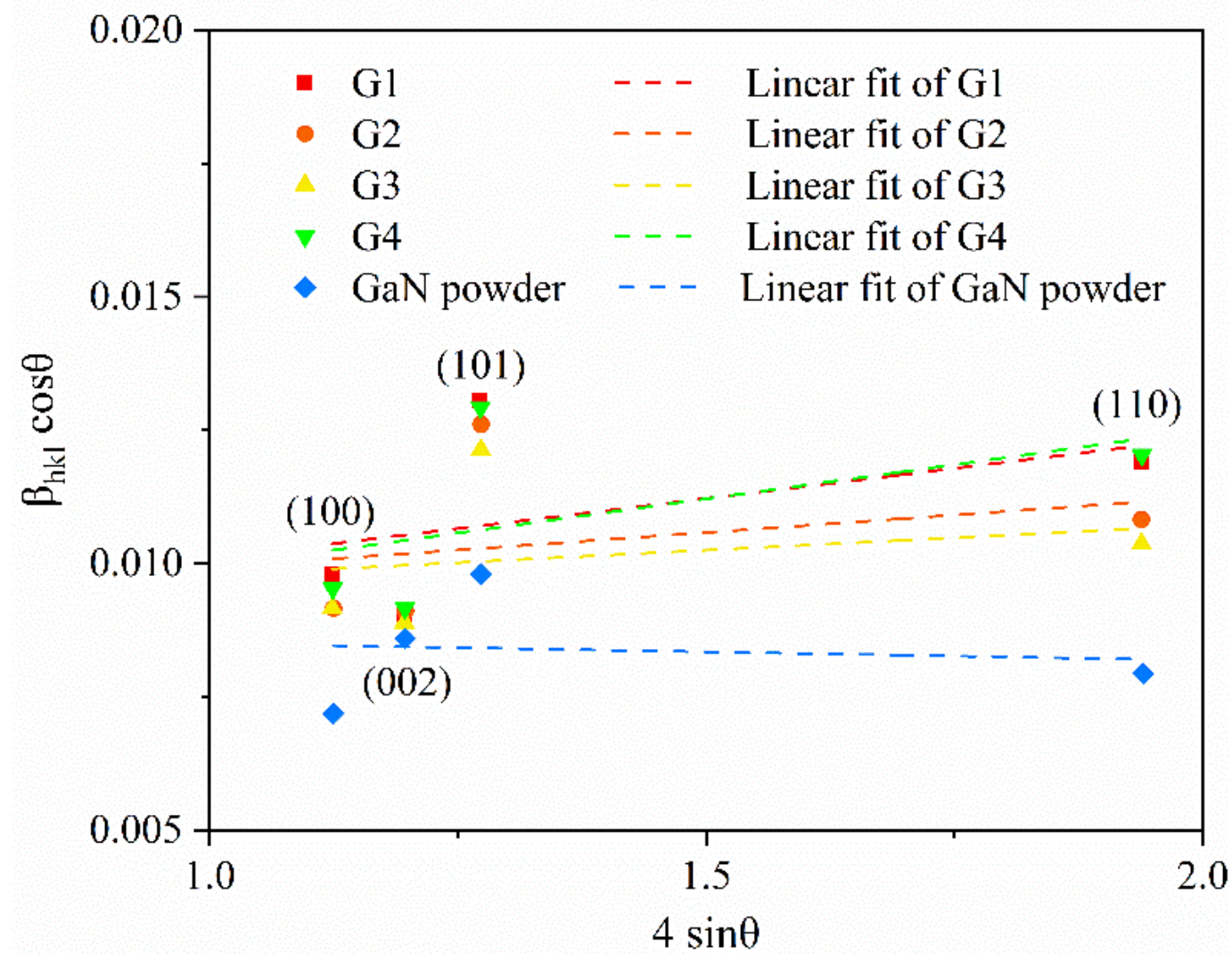

Fig. 13 Evolution of the Williamson-Hall plot for the coatings and GaN powder. 


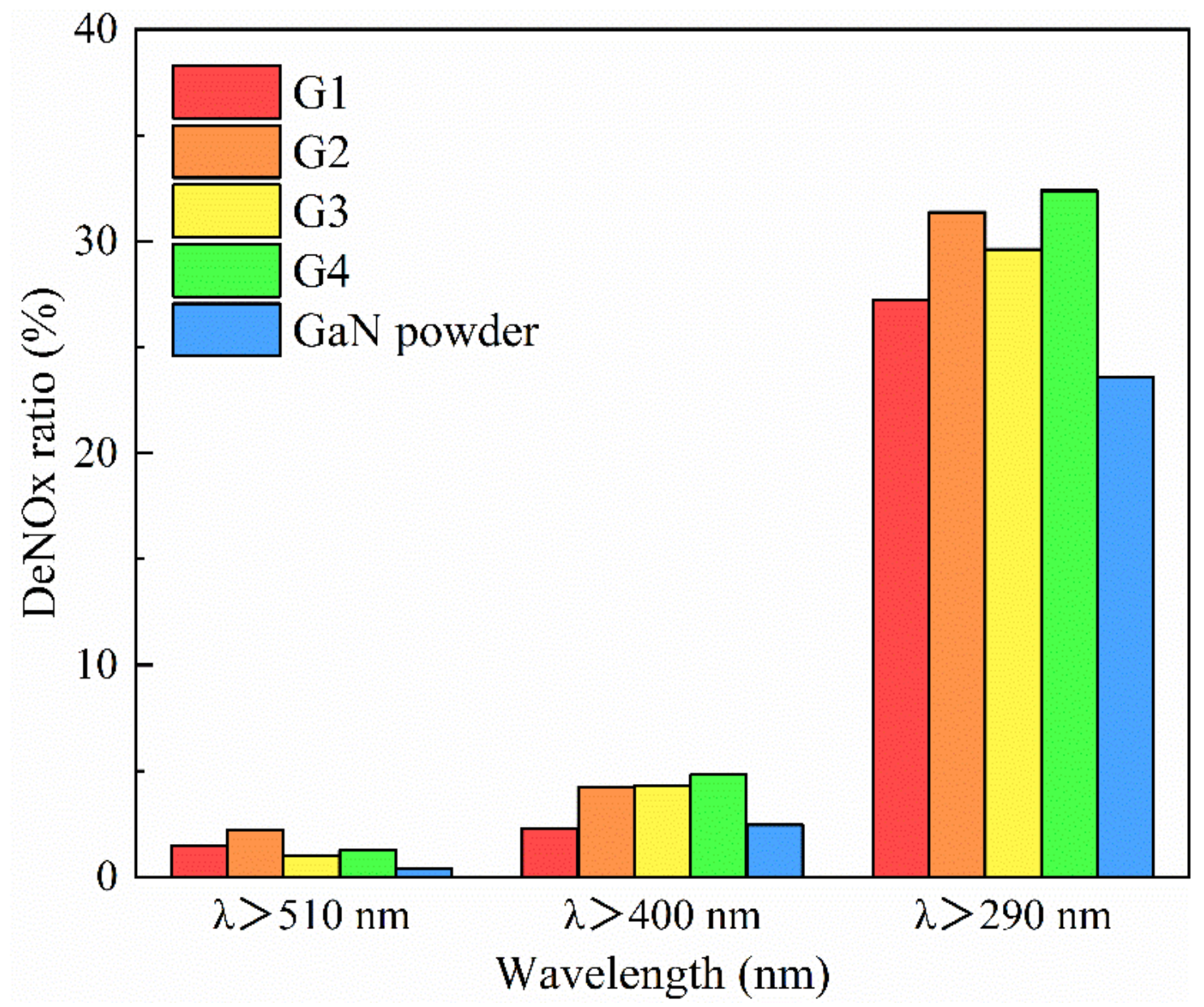

Fig. 14 Photocatalytic properties of each cold-sprayed specimen and GaN powder evaluated by NOx decomposition tests. 
(a)

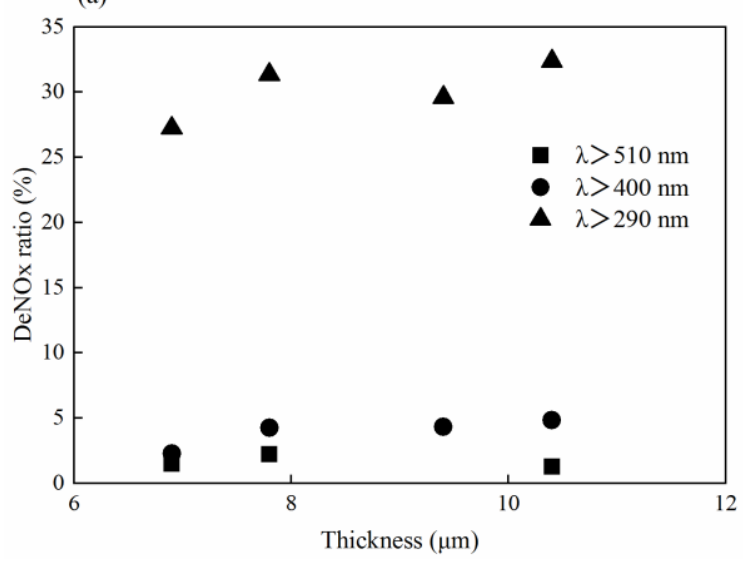

(b)

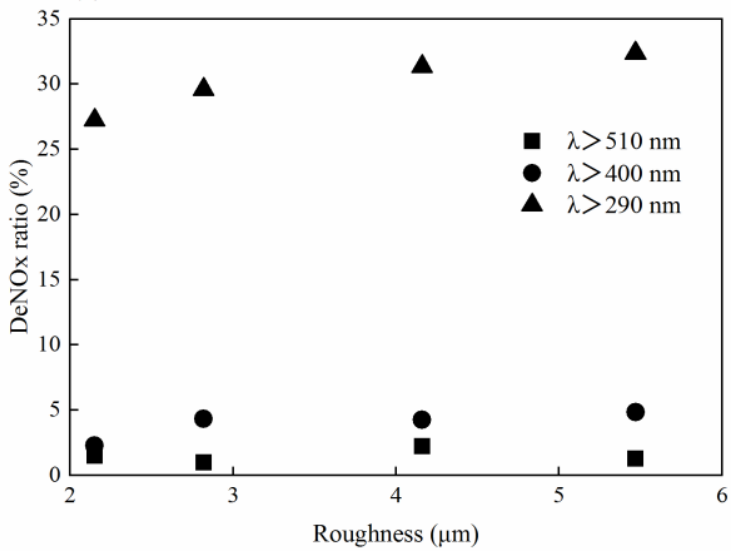

Fig. 15 Evolution of the deNOx ratio with respect to the (a) thickness and (b) roughness of the coatings. 